Review

\title{
Hierarchical Architecturing for Layered Thermoelectric Sulfides and Chalcogenides
}

\section{Priyanka Jood and Michihiro Ohta *}

Energy Technology Research Institute, National Institute of Advanced Industrial Science and Technology (AIST), Tsukuba, Ibaraki 305-8568, Japan; E-Mail: p.jood@aist.go.jp

* Author to whom correspondence should be addressed; E-Mail: ohta.michihiro@aist.go.jp; Tel.: +81-29-861-5663; Fax: +81-29-861-5340.

Academic Editor: Kunihito Koumoto

Received: 4 February 2015 / Accepted: 26 February 2015 / Published: 16 March 2015

\begin{abstract}
Sulfides are promising candidates for environment-friendly and cost-effective thermoelectric materials. In this article, we review the recent progress in all-length-scale hierarchical architecturing for sulfides and chalcogenides, highlighting the key strategies used to enhance their thermoelectric performance. We primarily focus on $\mathrm{TiS}_{2}$-based layered sulfides, misfit layered sulfides, homologous chalcogenides, accordion-like layered Sn chalcogenides, and thermoelectric minerals. $\mathrm{CS}_{2}$ sulfurization is an appropriate method for preparing sulfide thermoelectric materials. At the atomic scale, the intercalation of guest atoms/layers into host crystal layers, crystal-structural evolution enabled by the homologous series, and low-energy atomic vibration effectively scatter phonons, resulting in a reduced lattice thermal conductivity. At the nanoscale, stacking faults further reduce the lattice thermal conductivity. At the microscale, the highly oriented microtexture allows high carrier mobility in the in-plane direction, leading to a high thermoelectric power factor.
\end{abstract}

Keywords: thermoelectrics; $\mathrm{CS}_{2}$ sulfurization; thermoelectric sulfides; misfit layered chalcogenides; homologous chalcogenides; accordion-like layered chalcogenides; thermoelectric minerals; intercalation; crystal-structural evolution; low-energy atomic vibration; stacking fault; oriented texture 


\section{Introduction}

The growing demand for energy throughout the world is causing an energy crisis and aggravating environmental burden. However, more than $50 \%$ of the primary energy supplied is not utilized and is wasted in the form of heat. Solid-state devices based on thermoelectrics can directly convert the waste heat generated from various sources into useful electrical energy and can thus provide a new approach to improving energy management and sustainability while reducing greenhouse-gas emissions [1-5]. Currently, thermoelectric devices are found only in niche applications because thermoelectric materials show low efficiency and mainly consist of toxic and scarce (expensive) elements. Therefore, extensive efforts have been devoted to develop high-efficiency, environment-friendly, and cost-effective thermoelectric materials for large-scale practical applications, such as waste-heat recovery in vehicles and industries.

The thermoelectric figure of merit $(Z T)$ expresses the efficiency of thermoelectric materials and is defined as $Z T=\left(S^{2} / \rho \kappa_{\text {total }}\right) T$, where $S, \rho, \kappa_{\text {total }}$, and $T$ are the Seebeck coefficient, electrical resistivity, total thermal conductivity, and absolute temperature, respectively. An increase in the quantity $S^{2} / \rho$, which is known as the thermoelectric power factor, leads to an increase in the electrical performance. The $S^{2} / \rho$ is typically optimized by tuning the carrier concentration of materials. The $\kappa$ total is the sum of two parts: the charge carriers transporting heat (i.e., electronic thermal conductivity, $\left.\kappa_{\mathrm{el}}\right)$ and phonons traveling through the lattice (i.e., lattice thermal conductivity, $\kappa_{\text {lat }}$ ). Therefore, $\kappa_{\text {total }}=\kappa_{\mathrm{el}}+\kappa_{\text {lat }}$. The former is directly related to $\rho$ and can be estimated using the Wiedemann-Franz law: $\kappa_{\mathrm{el}}=L T / \rho$, where $L$ is the Lorenz number. Therefore, one way to reduce the $\kappa$ total is to minimize $\kappa$ lat, which is a carrier-independent parameter. In order to increase $S^{2} / \rho$ and reduce $\kappa_{\text {lat }}$, thermoelectric materials have been strategically developed with the phonon glass-electron crystal (PGEC) concept proposed by Slack [6]. A PGEC system consists of an electron crystal region and a phonon glass region. The electron crystal region allows carrier transmission, resulting in high carrier mobility and high $S^{2} / \rho$. The phonon glass region effectively scatters phonons, resulting in low $\kappa_{\text {lat. }}$ The PGEC concept has been realized using three methods: nanoblock integration, a nano- and meso-structuring/panoscopic approach, and rattling/low-energy atomic vibration.

Layered cobaltite oxides such as $\mathrm{Na}_{x} \mathrm{CoO}$ and $\mathrm{Ca}-\mathrm{Co}-\mathrm{O}$ have been demonstrated to be promising high-temperature thermoelectric materials [7-13]. An important advantage of thermoelectric oxides is their high chemical stability in air over a wide temperature range of 300-1200 K. The high ZT of these oxides originates from the integration of physical properties of the metallic electron-crystal nanoblock layer and disordered phonon-glass nanoblock layer. While the metallic Co-O nanoblock layers provide a high $S^{2} / \rho$, the disordered $\mathrm{Na}$ and $\mathrm{Ca}-\mathrm{Co}-\mathrm{O}$ nanoblock layers scatter phonons and reduce $\kappa_{\text {lat }}$ [10-13]. The impact of layered oxides has generated considerable interest in layered compounds, particularly layered sulfides and chalcogenides. The covalency generally increases when moving from oxides to sulfides and chalcogenides; therefore, the layered sulfides and chalcogenides show lower $\rho$ and higher $S^{2} / \rho[14]$.

PbTe-based materials represent one of the most successful examples of nano- and meso-structuring [15-21]. The insertion of endotaxial nanostructures in $\mathrm{PbTe}$ bulk materials causes the effective scattering of short-mean-free-path phonons without affecting the carrier mobility. Moreover, long-mean-free-path phonons are scattered at grain boundaries by controlling and fine-tuning the mesoscale architecture of nanostructured materials. As a result, the all-length-scale hierarchical 
architecture (panoscopic approach) in $\mathrm{PbTe}$ bulk thermoelectric materials causes a significant reduction in $\kappa$ lat and dramatically increases $Z T$ to an exceptionally high value of 2.2 at $915 \mathrm{~K}$ [17].

Skutterudites and clathrates are highly promising for practical thermoelectric devices operating in the intermediate temperature range of 573-973 K [22-28]. These systems contain large cages of host atoms in their crystal structures. Filling the large cages with guest atoms reduces $\kappa$ lat because the guest atoms rattle at low energy inside the cages and effectively scatter phonons. A very high ZT of 1.9 at $835 \mathrm{~K}$ was achieved in the skutterudite $\mathrm{Sr}_{0.09} \mathrm{Ba}_{0.11} \mathrm{Yb}_{0.05} \mathrm{Co}_{4} \mathrm{Sb}_{12}$ [27], and a conversion efficiency of $7 \%$ was demonstrated in a skutterudite-based thermoelectric module [28].

This review discusses recent progress in an intriguing new class of thermoelectric materials, layered chalcogenides. Among the layered chalcogenides, we primarily focus on the sulfide systems because sulfur is an environment-friendly and cost-effective element. Figure 1 shows the crystal structures of the thermoelectric sulfides and chalcogenides addressed in this article, including layered sulfide $\mathrm{TiS}_{2}$, misfit layered sulfide $[\mathrm{LaS}]_{1.14} \mathrm{NbS}_{2}$, a member of cannizzarite homologous series $\mathrm{Pb}_{5} \mathrm{Bi}_{6} \mathrm{Se}_{14}$, accordion-like layered selenide $\mathrm{SnSe}$, and thermoelectric mineral $\mathrm{Cu}_{12} \mathrm{Sb}_{4} \mathrm{~S}_{13}$. The nanoblock integration, nano- and meso-structuring/panoscopic approach, and rattling/low-energy atomic vibration to layered sulfides and chalcogenides are important guidance for $Z T$ enhancement through all-length-scale hierarchical architecture.

(a)

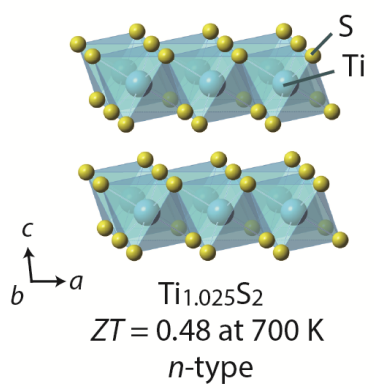

(b)

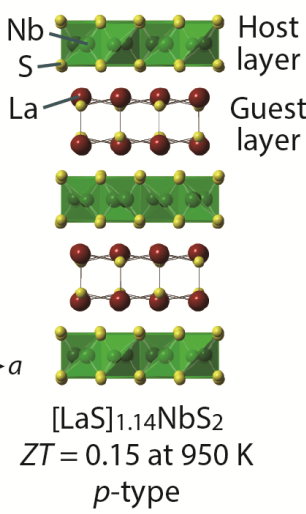

(c)

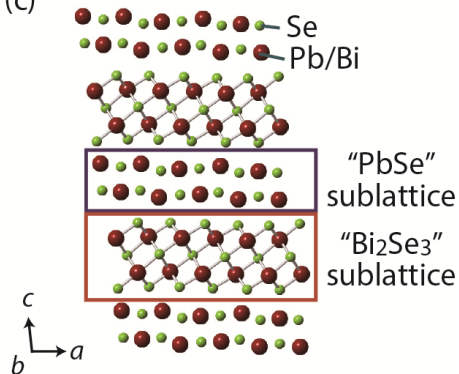

$\mathrm{Pb}_{5} \mathrm{Bi}_{6} \mathrm{Se}_{14}$

$Z T=0.46$ at $705 \mathrm{~K}$

$n$-type (d)
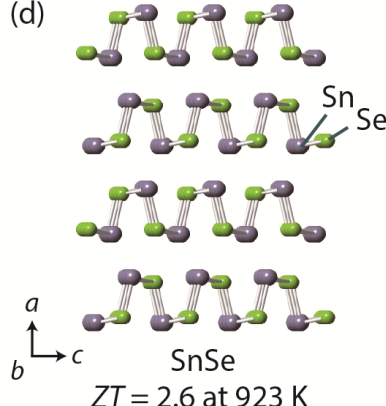

p-type

(e)

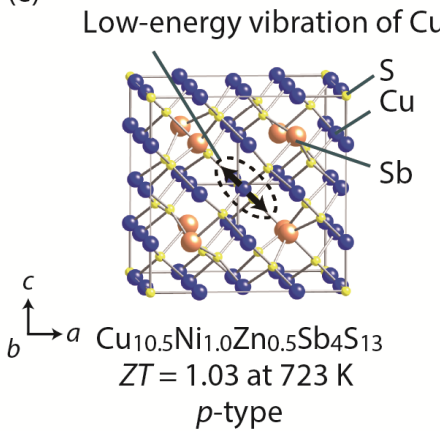

Figure 1. Crystal structures of the thermoelectric sulfides and chalcogenides addressed in this article: (a) $\mathrm{TiS}_{2}$ [29,30]; (b) [LaS]1.14NbS2 [31,32]; (c) $\mathrm{Pb}_{5} \mathrm{Bi}_{6} \mathrm{Se}_{14}$ [33,34]; (d) $\mathrm{SnSe}$ [35]; and (e) $\mathrm{Cu}_{12} \mathrm{Sb}_{4} \mathrm{~S}_{13}[36,37]$. Sizes of atoms in this figure are arbitrary. 


\section{2. $\mathrm{CS}_{2}$ Sulfurization and Pressurized Sintering}

We first discuss the synthesis and processing of thermoelectric sulfides, which drastically affects their properties. In the case of $\mathrm{TiS}_{2}$-based layered sulfides, a single crystal can be grown using the chemical-vapor-transport method with $\mathrm{I}_{2}$ as the transport agent [38-41]. Polycrystalline $\mathrm{TiS}_{2}$-based layered sulfides have been commonly prepared by melting stoichiometric amounts of the constituent elements in evacuated and sealed quartz tubes at 905-1273 K, followed by pressurized sintering at 873-1173 K [30,42-47]. However, these methods are difficult to apply because of the large difference in vapor pressure between metals and sulfur; consequently, there is less motivation for researchers in the thermoelectric community to investigate thermoelectric sulfides further. In this review, we focused on $\mathrm{CS}_{2}$ sulfurization, which is a low-temperature preparation method for thermoelectric sulfides [29,48-53].

The temperature dependence of the standard free-energy change $\left(\Delta G^{\circ}\right)$ for the sulfurization of $\mathrm{TiO}_{2}$, $\mathrm{La}_{2} \mathrm{O}_{3}, \mathrm{CeO}_{2}$, and $\mathrm{Pr}_{6} \mathrm{O}_{11}$ with $\mathrm{CS}_{2}$ and $\mathrm{H}_{2} \mathrm{~S}$ gases, calculated from thermodynamic data $[54,55]$, is shown in Figure 2 [29,51,52]. The value of $\Delta G^{\circ}$ for $\mathrm{CS}_{2}$ sulfurization is lower than that for $\mathrm{H}_{2} \mathrm{~S}$ sulfurization in the temperature range of $600-1300 \mathrm{~K}$. For example, the values of $\Delta G^{\circ}$ at $1100 \mathrm{~K}$ for the sulfurization of $\mathrm{La}_{2} \mathrm{O}_{3}$ with $\mathrm{CS}_{2}$ and $\mathrm{H}_{2} \mathrm{~S}$ are -126 and $-26 \mathrm{~kJ} \cdot \mathrm{mol}^{-1}$, respectively, which implies that $\mathrm{CS}_{2}$ gas is a powerful sulfurizing agent for oxides, allowing the low-temperature formation of sulfides.

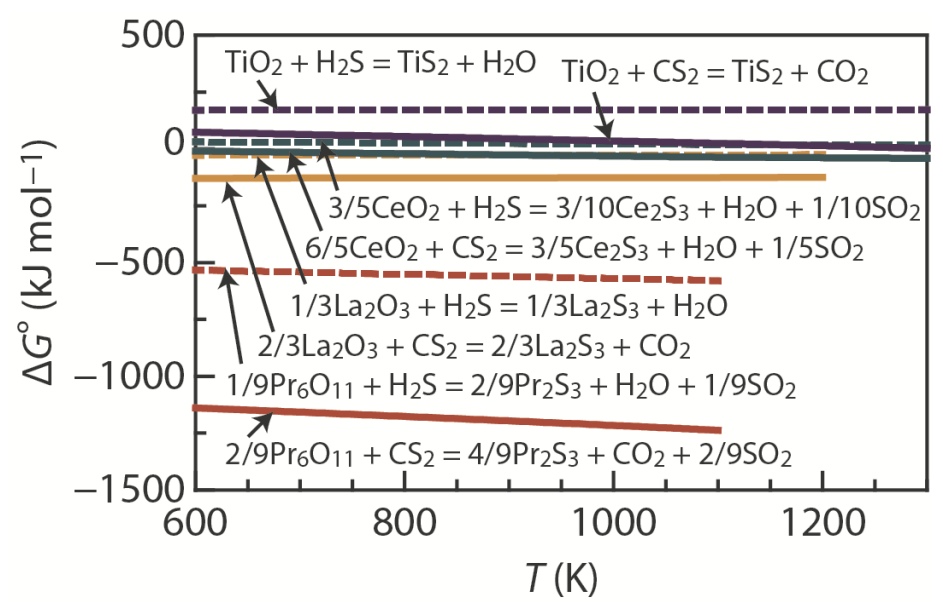

Figure 2. Temperature dependence of the standard free-energy change $\left(\Delta G^{\circ}\right)$ for the sulfurization of $\mathrm{TiO}_{2}$ [29], $\mathrm{La}_{2} \mathrm{O}_{3}, \mathrm{CeO}_{2}$ [51], and $\mathrm{Pr}_{6} \mathrm{O}_{11}$ [52] with $\mathrm{CS}_{2}$ and $\mathrm{H}_{2} \mathrm{~S}$.

A schematic diagram of the experimental apparatus used for $\mathrm{CS}_{2}$ sulfurization is shown in Figure 3. The apparatus was referenced previously in a report by Hirai et al. [51]. The starting oxide powders were placed in quartz boats and set in a quartz reaction tube. The quartz tube was evacuated and purged with Ar gas. The powders were heated to $573 \mathrm{~K}$ under Ar gas flow. A mixture of $\mathrm{CS}_{2}$ and Ar gases was introduced into the quartz tube as soon as the powders reached $573 \mathrm{~K}$. The $\mathrm{CS}_{2}$ gas was obtained by bubbling Ar carrier gas through $\mathrm{CS}_{2}$ liquid. Single phases of $\mathrm{TiS}_{2}$, $[\mathrm{LaS}]_{1.20} \mathrm{CrS}_{2}$, and $[\mathrm{LaS}]_{1.14 \mathrm{NbS}_{2} \text { were }}$ successfully prepared through $\mathrm{CS}_{2}$ sulfurization at $1073 \mathrm{~K}$ for 4-12 h [29,32].

Powders of layered thermoelectric sulfides and chalcogenides were sintered under uniaxial pressure to obtain high-density compacts. Figure 4 shows scanning electron microscopy (SEM) micrographs of the fractured section of sintered compacts of $\mathrm{Ti}_{1.008} \mathrm{~S}_{2}$ [29], [LaS ${ }_{1.20} \mathrm{CrS}_{2}$ [32], and $\mathrm{Pb}_{5} \mathrm{Bi}_{6} \mathrm{Se}_{14}$ [34] that were fractured parallel to the pressure direction. The micrographs reveal a dense structure and 
well-organized microtexture, indicating that the pressurized sintering promotes densification and grain orientation. The XRD patterns show that the crystalline $c$-axis is preferentially oriented along the pressing (out-of-plane) direction [29,32,34]. A centrifugal heating technique also provides the dense samples with highly oriented microtexture [56]. The highly oriented microtextures allow high carrier mobility in the in-plane direction, leading to a high thermoelectric power factor.

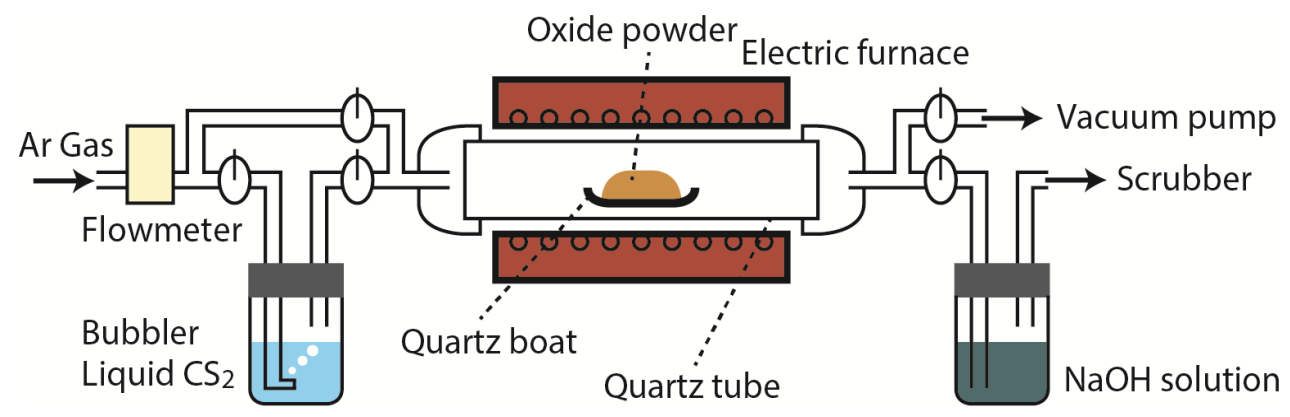

Figure 3. Schematic diagram of the experimental apparatus used for $\mathrm{CS}_{2}$ sulfurization. The apparatus was referenced previously in a report by Hirai et al. [51].
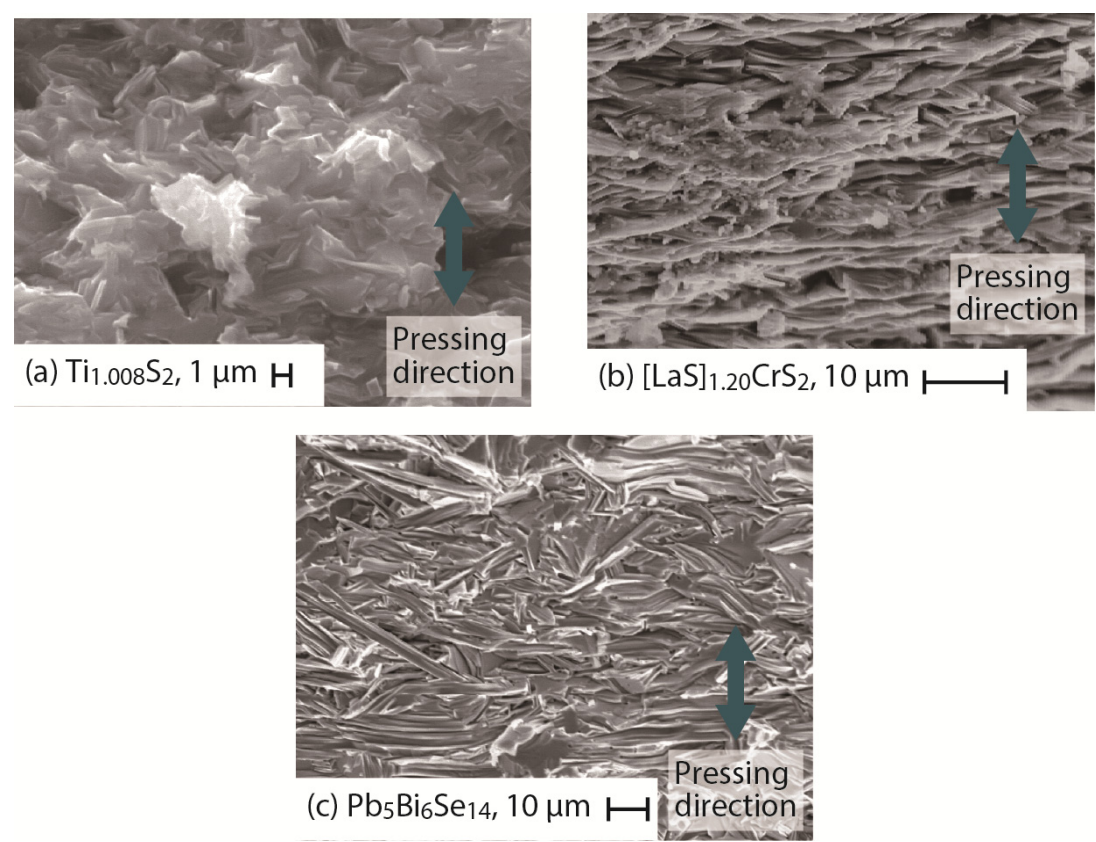

Figure 4. Scanning electron micrographs of the fractured section of sintered compacts of (a) $\mathrm{Ti}_{1.008} \mathrm{~S}_{2}[29]$; (b) $[\mathrm{LaS}]_{1.20} \mathrm{CrS}_{2}[32]$; and (c) $\mathrm{Pb}_{5} \mathrm{Bi}_{6} \mathrm{Se}_{14}$ [34].

\section{TiS $_{2}$-Based Layered Sulfides}

Because $\mathrm{TiS}_{2}$-based layered sulfides are primarily composed of earth-abundant, low-toxicity, and light elements, they will pave the way for environment-friendly, cost-effective, and lightweight thermoelectric devices [29,30,39-47,56-66]. The two-dimensional crystal structure of these systems is a great example in which the thermoelectric performance can be improved through nanoblock integration and hierarchical architecturing. The recently developed $\mathrm{TiS}_{2}$-based sulfides with high thermoelectric figure of merit $(Z T)$ are summarized in Figure 5. In 2001, Imai et al. [40] demonstrated a high power factor $\left(S^{2} / \rho\right)$ of $\sim 3710 \mu \mathrm{W} \cdot \mathrm{K}^{-2} \cdot \mathrm{m}^{-1}$ at $300 \mathrm{~K}$ in a single crystal of near-stoichiometric $\mathrm{TiS}_{2}$, which is 
comparable to that of commercially available thermoelectric materials such as $\mathrm{Bi}_{2} \mathrm{Te}_{3}$. However, the single crystal shows a high lattice thermal conductivity $\kappa_{\text {lat }}$ of $\sim 6.35 \mathrm{~W} \cdot \mathrm{K}^{-1} \cdot \mathrm{m}^{-1}$, which limits the $Z T$ to $\sim 0.16$ at $300 \mathrm{~K}$ (Table 1). Recently, the intercalation of guest atoms and guest layers into TiS2 layers was found to reduce the $\kappa_{\text {lat }}$ of these systems, similar to layered cobaltite oxides [7-13]. For example, $\mathrm{Cu}$ intercalation reduces $\kappa_{\text {lat }}$ and enhances $Z T$ to $\sim 0.5$ at $823 \mathrm{~K}$ [44].

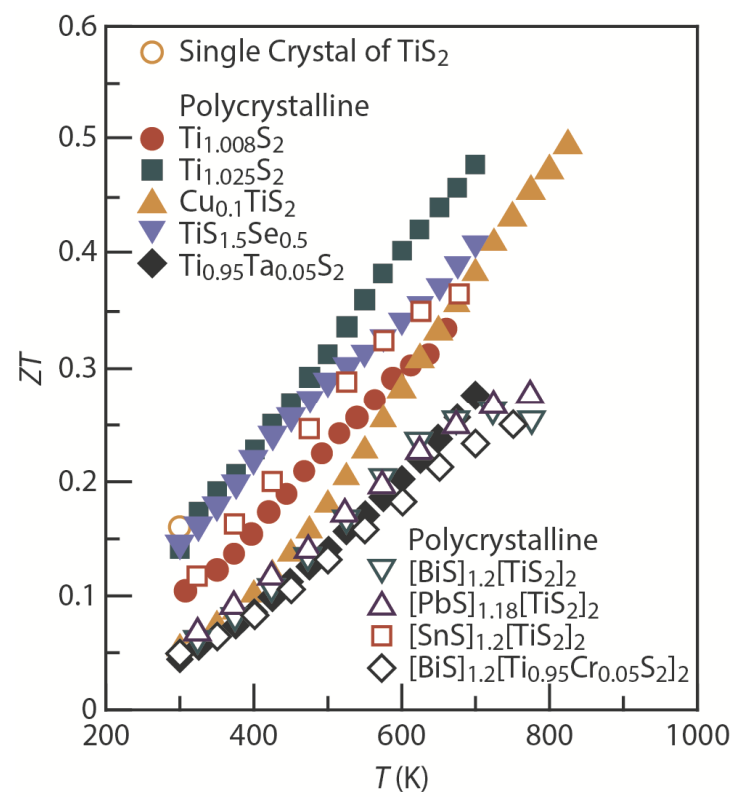

Figure 5. Current state-of-the-art $\mathrm{TiS}_{2}$-based layered sulfides. Temperature dependence of the thermoelectric figure of merit $(Z T)$ in the in-plane ( $a b$-plane) direction for single-crystal $\mathrm{TiS}_{2}$ [40] and polycrystalline $\mathrm{Ti}_{1.008} \mathrm{~S}_{2}$ [29], $\mathrm{Ti}_{1.025} \mathrm{~S}_{2}$ [30], Cu0.1 $\mathrm{TiS}_{2}$ [44], $\mathrm{TiS}_{1.5} \mathrm{Se}_{0.5}$ [45], $\mathrm{Ti}_{0.95} \mathrm{Ta}_{0.05} \mathrm{~S}_{2}$ [46], [BiS $]_{1.2}\left[\mathrm{TiS}_{2}\right]_{2}$ [42], $[\mathrm{PbS}]_{1.18}\left[\mathrm{TiS}_{2}\right]_{2}$ [42], [SnS $]_{1.2}\left[\mathrm{TiS}_{2}\right]_{2}$ [43], and $[\mathrm{BiS}]_{1.2}\left[\mathrm{Ti} 0.95 \mathrm{Cr} 0.05 \mathrm{~S}_{2}\right]_{2}[66]$.

Table 1. Seebeck coefficient $(S)$, electrical resistivity $(\rho)$, carrier mobility $(\mu)$, power factor $\left(S^{2} / \rho\right)$, lattice thermal conductivity ( $\left.\kappa_{\text {lat }}\right)$, and thermoelectric figure of merit $(Z T)$ at room temperature in the in-plane ( $a b$-plane) and out-of-plane ( $c$-axis) directions for a single crystal of nearly stoichiometric $\mathrm{TiS}_{2}[40]$ and polycrystalline $\mathrm{Ti}_{1.008} \mathrm{~S}_{2}$ [29].

\begin{tabular}{|c|c|c|c|c|c|c|c|}
\hline Sample & Direction & $\begin{array}{c}S \\
\left(\mu V \cdot K^{-1}\right)\end{array}$ & $\begin{array}{c}\rho \\
(\mu \Omega \cdot m)\end{array}$ & $\begin{array}{c}\mu \\
\left(\mathrm{cm}^{2} \cdot \mathbf{V}^{-1} \cdot \mathbf{s}^{-1}\right)\end{array}$ & $\begin{array}{c}S^{2} / \rho \\
\left(\mu \mathbf{W} \cdot \mathbf{K}^{-2} \cdot \mathbf{m}^{-1}\right)\end{array}$ & $\begin{array}{c}\mathbf{K}_{\text {lat }} \\
\left(\mathbf{W} \cdot \mathbf{K}^{-1} \cdot \mathbf{m}^{-1}\right)\end{array}$ & $Z T$ \\
\hline Single crystal & In-plane & -251 & 17 & 15 & 3710 & 6.35 & 0.16 \\
\hline Single crystal & Out-of-plane & - & 13,000 & 0.017 & - & 4.21 & - \\
\hline Polycrystalline & In-plane & -80 & 6.2 & 2.3 & 1030 & 1.5 & 0.12 \\
\hline Polycrystalline & Out-of-plane & -84 & 11 & 1.2 & 630 & 1.3 & 0.10 \\
\hline
\end{tabular}

The crystal structure of $\mathrm{TiS}_{2}$ consists of a stacked $\mathrm{CdI}_{2}$-type layer along the crystalline $c$-axis and is shown in Figure 1a. The $\mathrm{TiS}_{2}$ phase has a wide range of chemical compositions ranging from stoichiometric to Ti-rich: $\mathrm{Ti}_{1+x} \mathrm{~S}_{2}$ with $0 \leq x<0.1$ [67-69]. Because the $\mathrm{TiS}_{2}$ layer is weakly stacked through van der Waals forces, the excess $\mathrm{Ti}$ atoms occupy the space between $\mathrm{TiS}_{2}$ layers. The lattice parameter $a$ monotonically increases from $0.3405 \mathrm{~nm}$ for $\mathrm{Ti}_{1.001} \mathrm{~S}_{2}$ to $0.3412 \mathrm{~nm}$ for $\mathrm{Ti}_{1.093} \mathrm{~S}_{2}$, and $c$ increases from $0.5691 \mathrm{~nm}$ for $\mathrm{Ti}_{1.001} \mathrm{~S}_{2}$ to $0.5711 \mathrm{~nm}$ for $\mathrm{Ti}_{1.093} \mathrm{~S}_{2}[70]$. 
To interpret the thermoelectric properties of $\mathrm{TiS}_{2}$, we used the following formulas for approximations of electrical resistivity $\rho$, carrier mobility $\mu$, Кlat, and Seebeck coefficient $S$ [71-73]:

$$
\begin{gathered}
\frac{1}{\rho}=n e \mu \\
\mu=\frac{e \tau_{\mathrm{e}}}{m^{*}} \\
\kappa_{\text {lat }}=\frac{1}{3} C_{\mathrm{v}} v_{\mathrm{a}} l_{\mathrm{p}} \\
S=\frac{8 \pi^{2} k_{\mathrm{B}}^{2}}{3 e h^{2}} m^{*} T\left(\frac{\pi}{3 n}\right)^{2 / 3}
\end{gathered}
$$

where $n, e, \tau_{\mathrm{e}}, m^{*}, C_{\mathrm{v}}, v_{\mathrm{a}}, l_{\mathrm{p}}, k_{\mathrm{B}}$, and $h$ are the carrier concentration, electronic charge, relaxation time of charge carriers, effective mass, heat capacity at constant pressure, average sound velocity, mean free path of phonons, Boltzmann constant, and Planck's constant, respectively. These relationships are derived from the parabolic band model and energy-independent scattering time for metals and degenerate semiconductors.

The layered crystal structure results in highly anisotropic electrical and thermal transport properties $[29,40,43]$. Table 1 lists $S, \rho, \mu, S^{2} / \rho, \kappa_{\text {lat, }}$, and $Z T$ at room temperature in the in-plane (ab-plane) and out-of-plane (c-axis) directions for a single crystal of nearly stoichiometric $\mathrm{TiS}_{2}[40]$ and polycrystalline $\mathrm{Ti}_{1.008 \mathrm{~S}_{2}}$ [29]. The polycrystalline sample possesses a well-organized microtexture (Figure 4a) with the crystalline $a b$-plane preferentially oriented along the in-plane direction. The room-temperature $n$ of the single crystal and polycrystalline samples are $2.8 \times 10^{20} \mathrm{~cm}^{-3}$ and $\sim 4.5 \times 10^{21} \mathrm{~cm}^{-3}$, respectively. For single crystal, the out-of-plane $\rho(\sim 13,000 \mu \Omega \cdot \mathrm{m})$ is nearly 750 times higher than the in-plane $\rho(\sim 17 \mu \Omega \cdot \mathrm{m})$, and the out-of-plane $\mu\left(\sim 0.017 \mathrm{~cm}^{2} \cdot \mathrm{V}^{-1} \cdot \mathrm{s}^{-1}\right)$ is significantly lower than the in-plane $\mu\left(\sim 15 \mathrm{~cm}^{2} \cdot \mathrm{V}^{-1} \cdot \mathrm{s}^{-1}\right)$ at $300 \mathrm{~K}$. Moreover, the out-of-plane $\kappa_{\text {lat }}\left(\sim 4.21 \mathrm{~W} \mathrm{~K}^{-1} \cdot \mathrm{m}^{-1}\right)$ is slightly lower than the in-plane $\kappa_{\text {lat }}\left(\sim 6.35 \mathrm{~W} \cdot \mathrm{K}^{-1} \cdot \mathrm{m}^{-1}\right)$ at $300 \mathrm{~K}$. The highly oriented polycrystalline sample also exhibits lower $\rho$, higher $\mu$, and higher $\kappa_{\text {lat }}$ in the in-plane direction. The high value of the out-of-plane $\rho$ and low value of the out-of-plane $\kappa_{\text {lat }}$ are principally due to the reduced relaxation time (reduced mean free path) resulting from the significant electron and phonon scatterings, respectively, at the interfaces between the TiS 2 layers (see Equations (1)-(3)). The sign of $S$ is negative for both samples, confirming $n$-type carrier transport. Unlike $\rho$ and $\kappa_{\text {lat, }} S$ was found to be insensitive to the crystal orientation in the sintered compacts; as there is no relationship between $S$ and $\tau$ in Equation (1), $S$ is nearly isotropic. The in-plane $S\left(\sim-80 \mu \mathrm{V} \cdot \mathrm{K}^{-1}\right)$ is nearly the same as the out-of-plane $S\left(\sim-84 \mu \mathrm{V} \cdot \mathrm{K}^{-1}\right)$ at $300 \mathrm{~K}$. The higher $S^{2} / \rho\left(\sim 1030 \mu \mathrm{W} \cdot \mathrm{K}^{-2} \cdot \mathrm{m}^{-1}\right)$ and higher $Z T(\sim 0.12)$ in the in-plane direction at $300 \mathrm{~K}$ for polycrystalline $\mathrm{Ti}_{1.008} \mathrm{~S}_{2}$ is due to the lower in-plane $\rho$ and insensitivity of $S$ to the crystal orientation.

The intercalated Ti provides $n$-type carriers to the system; therefore, $n$ can be tuned to optimize $S^{2} / \rho$ by self-intercalation. Figure 6 shows the room-temperature $S, \rho$, and $S^{2} / \rho$ plotted against $n$. The solid line in Figure 6a represents the values calculated using Equation (4) with $m^{*} / m_{0}\left(m_{0}\right.$ is the free electron mass) equal to 2.88 when $n$ is greater than $5 \times 10^{20} \mathrm{~cm}^{-3}$ [74-76]. The measured values fall on this calculated line. An increase in Ti content results in an increase in $n$ and, hence, a decrease in $S$ and $\rho$. The $S^{2} / \rho$ peaks around $n \sim 2.8 \times 10^{21} \mathrm{~cm}^{-3}$ in $\mathrm{Ti}_{1+x} \mathrm{~S}_{2}$ and reaches a value of $\sim 3700 \mu \mathrm{W} \cdot \mathrm{K}^{-2} \cdot \mathrm{m}^{-1}$. 

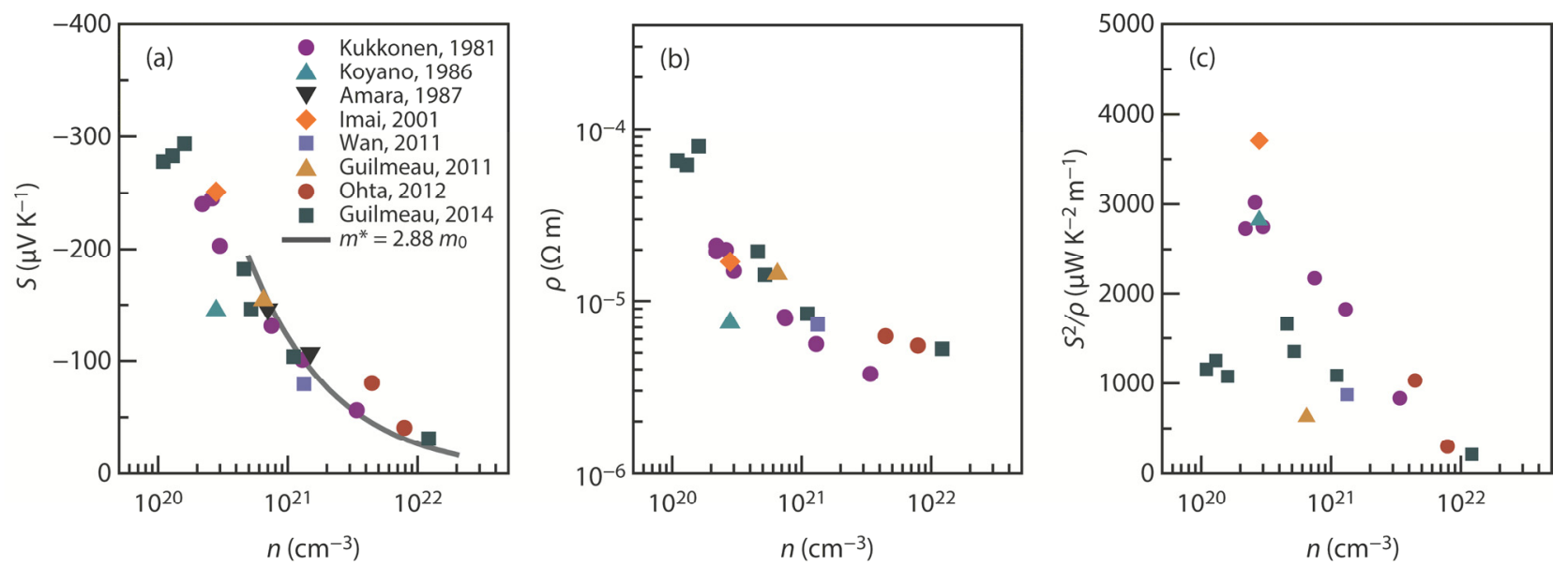

Figure 6. (a) Seebeck coefficient $(S)$; (b) electrical resistivity $(\rho)$; and (c) power factor $\left(S^{2} / \rho\right)$ plotted against the carrier concentration $(n)$ at $300 \mathrm{~K}$ in the in-plane (ab-plane) direction for $\mathrm{Ti}_{1+x} \mathrm{~S}_{2}[29,30,41,43,44,75-77]$. The solid line in (a) represents the values calculated using Equation (4) with $\mathrm{m}^{*} / \mathrm{m}_{0}$ ( $m_{0}$ is the free electron mass) equal to 2.88 when $n$ is greater than $5 \times 10^{20} \mathrm{~cm}^{-3}[74-76]$.

One way to reduce $\kappa_{\text {lat }}$ is the intercalation of guest atoms and guest layers into the host $\mathrm{TiS}_{2}$ layer $[42-44,65,66]$. For example, $\mathrm{Cu}$ intercalation reduces $\kappa_{\text {lat }}$ from $\sim 2.0 \mathrm{~W} \cdot \mathrm{K}^{-1} \cdot \mathrm{m}^{-1}$ for $\mathrm{TiS}_{2}$ to $\sim 1.7 \mathrm{~W} \cdot \mathrm{K}^{-1} \cdot \mathrm{m}^{-1}$ for $\mathrm{Cu}_{0.1} \mathrm{TiS}_{2}$, and $\mathrm{SnS}$ intercalation dramatically reduces $\kappa_{\text {lat }}$ to $\sim 1.0 \mathrm{~W} \cdot \mathrm{K}^{-1} \cdot \mathrm{m}^{-1}$ for $[\mathrm{SnS}]_{1.2}\left[\mathrm{TiS}_{2}\right]_{2}$ at $300 \mathrm{~K}$ (Figure 7a). Substitution is another way to reduce $\kappa_{\text {lat }}$ [45-47]; for example, the substitution of Ti by Ta slightly reduces $\kappa_{\text {lat }}$ to $\sim 1.8 \mathrm{~W} \cdot \mathrm{K}^{-1} \cdot \mathrm{m}^{-1}$ for Ti $0.95 \mathrm{Ta} 0.05 \mathrm{~S}_{2}$ at $300 \mathrm{~K}$ (Figure 7b).
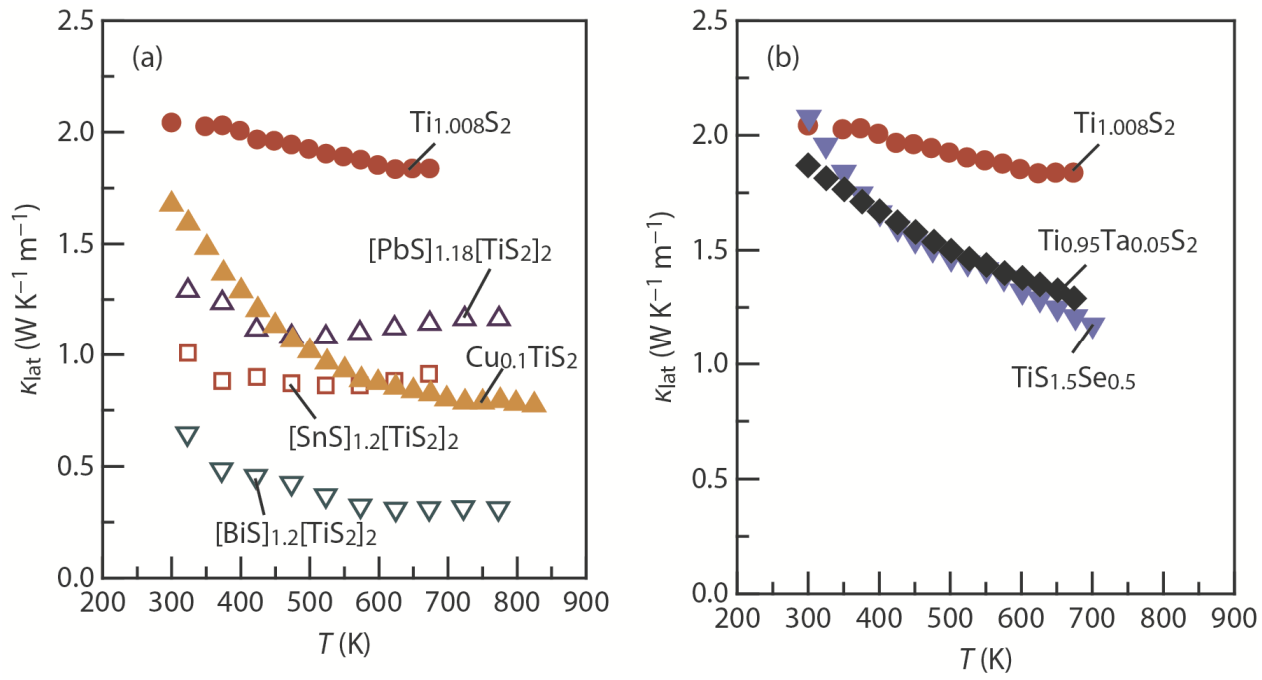

Figure 7. Temperature dependence of the lattice thermal conductivity $\left(\kappa_{\text {lat }}\right)$ in the in-plane (ab-plane) direction for $\mathrm{Ti}_{1.008} \mathrm{~S}_{2}$ [29]: (a) intercalated systems [BiS $]_{1.2}\left[\mathrm{TiS}_{2}\right]_{2}$ [42], $[\mathrm{PbS}]_{1.18}\left[\mathrm{TiS}_{2}\right]_{2}[42],[\mathrm{SnS}]_{1.2}\left[\mathrm{TiS}_{2}\right]_{2}$ [43], and $\mathrm{Cu}_{0.1} \mathrm{TiS}_{2}$ [44]; (b) substituted systems $\mathrm{TiS}_{1.5} \mathrm{Se}_{0.5}[45]$ and $\mathrm{Ti}_{0.95} \mathrm{Ta}_{0.05} \mathrm{~S}_{2}[46]$.

The reduction in Klat through intercalation and substitution is limited; therefore, $Z T$ is below 0.5 . Future work should aim to develop new methods for a dramatic reduction in $\kappa_{\text {lat }}$ to achieve $Z T$ enhancement in $\mathrm{TiS}_{2}$-based layered sulfides. Recently, Koumoto et al. [64,66] have demonstrated 
that the stacking faults in the layers can be tuned to reduce the thermal conductivity. We believe that well-organized stacking faults can ideally reduce $\kappa$ lat and enhance ZT beyond 0.5 .

\section{Misfit Layered Sulfides $[\mathrm{MS}]_{1+m}\left[\mathrm{TS}_{2}\right]_{n}$}

$\mathrm{TiS}_{2}$-based layered sulfides are a part of a large family of misfit layered sulfides with a general formula $[\mathrm{MS}]_{1+m}\left[\mathrm{TS}_{2}\right]_{n}$, where $\mathrm{M}=\mathrm{Sn}, \mathrm{Pb}, \mathrm{Sb}, \mathrm{Bi}$, and rare-earth metals; $\mathrm{T}=\mathrm{Ti}, \mathrm{V}, \mathrm{Cr}, \mathrm{Nb}$, and $\mathrm{Ta}$; and $n=1,2,3$ [78]. These compounds consist of alternating MS and $\mathrm{TS}_{2}$ layers, which belong to separate subgroups; therefore, these compounds lack three-dimensional periodicity. The crystal-structure analysis of rare-earth misfit compound (MS) ${ }_{1+m} \mathrm{NbS}_{2}$ has been performed using different subgroups including the $(3+1)$-dimensional superspace group $[31,79,80]$, and different structural variants depending upon the intercalation layer were proposed. Miyazaki et al. [81] have reported a significant variation in the $c$-axis depending on the ionic radius of the rare-earth element. Previous results have shown that $\mathrm{NbS}_{2}$ [32,53,81,82], $\mathrm{TaS}_{2}[83,84]$, and $\mathrm{TiS}_{2}$ [42,43,65,66] sandwich structures show metallic conductivity, whereas $\mathrm{CrS}_{2}[32,85]$ and $\mathrm{VS}_{2}[78,85]$ sandwich structures show semiconducting properties. The crystal structure and physical properties of this misfit family were extensively studied in the 1990s [78]; however, not many reports on their thermoelectric properties exist to date. In recent years, the misfit layered sulfides have gained interest in the thermoelectric community for their PGEC behavior, where the intercalated $\mathrm{NaCl}$-type MS layer is primarily responsible for the disorder (reduction in $\kappa_{\text {lat }}$ ) and the $\mathrm{CdI}_{2}$-type $\mathrm{TS}_{2}$ layer behaves as a charge-carrier pathway $[86,87]$. The entire crystal structure is stabilized through charge transfer from the MS layer to the $\mathrm{TS}_{2}$ layer $[78,88]$. Through the concept of bond valences, it is established that the interlayer $\mathrm{La}-\mathrm{S}$ bond valences are much larger than the interlayer $\mathrm{M}-\mathrm{S}$ bond valences with $\mathrm{M}=\mathrm{Sn}$ or Bi [88-90], which makes the LnS-based misfit layered compounds $(\mathrm{Ln}=$ rare-earth metals) much more mechanically hard (due to strong interlayer bonding) than the SnS-, PbS-, BiS-, and SbS-based systems [88].

Thus far, only [MS $]_{1+m} \mathrm{NbS}_{2}$ with $\mathrm{M}=$ rare-earth elements [32,53,81]; [LaS $]_{1.2} \mathrm{CrS}_{2}$ [32]; and [MS $]_{1+m} \mathrm{TiS}_{2}$ with $\mathrm{M}=\mathrm{Sn}, \mathrm{Pb}$, or $\mathrm{Bi}[42,43,64-66]$ (discussed in the previous section) have been studied in depth for their thermoelectric properties. The thermoelectric properties of $[\mathrm{MS}]_{1+m} \mathrm{TS}_{2}(\mathrm{M}=\mathrm{La}, \mathrm{Yb} ; \mathrm{T}=\mathrm{Cr}, \mathrm{Nb})$ in the in-plane (ab-plane) and out-of-plane (c-axis) directions are summarized in Table $2 . \mathrm{The}^{\mathrm{NbS}} 2$ systems show $p$-type $S$, whereas $\mathrm{CrS}_{2}$ systems show $n$-type $S$. Among all compounds in the LnS-based series, $\left[\mathrm{Yb}_{2} \mathrm{~S}_{2}\right]_{0.62} \mathrm{NbS}_{2}$ shows the highest $Z T$ of $\sim 0.10$ at $300 \mathrm{~K}$ because it shows the highest $S^{2} / \rho$ [81]. The $S$ of the Yb sample is $\sim 35 \%-60 \%$ higher than those of samples consisting of the other elements in the lanthanide series at $300 \mathrm{~K}$. This is due to its slightly lower $n\left(\sim 5 \times 10^{20} \mathrm{~cm}^{-3}\right)$, the reason for which is not very well understood and requires further study. At $300 \mathrm{~K}$, a very low $\kappa$ lat $\sim 0.41 \mathrm{~W} \cdot \mathrm{K}^{-1} \cdot \mathrm{m}^{-1}$ is achievable for $\left[\mathrm{Yb}_{2} \mathrm{~S}_{2}\right]_{0.62} \mathrm{NbS}_{2}$, which reduces even further $\left(\sim 0.18 \mathrm{~W} \cdot \mathrm{K}^{-1} \cdot \mathrm{m}^{-1}\right)$ with the removal of $\sim 5 \%$ $\mathrm{Yb}$ and $\mathrm{S}$ from the $\left[\mathrm{Yb}_{2} \mathrm{~S}_{2}\right]$ layer, slightly enhancing the room-temperature $Z T$ to $\sim 0.11$. This is due to the high phonon scattering originating from the highly modulated structure and atomic deficiency. Further improvements in $Z T$ are expected at higher temperatures. 
Table 2. Seebeck coefficient $(S)$; electrical resistivity $(\rho)$; total thermal conductivity ( $\left.\kappa_{\text {total }}\right)$; lattice thermal conductivity ( $\kappa$ lat); power factor $\left(S^{2} / \rho\right)$; and thermoelectric figure of merit $(Z T)$ in the in-plane ( $a b$-plane) and out-of-plane ( $c$-axis) directions of state-of-the-art misfit layered sulfides: $[\mathrm{MS}]_{1+m} \mathrm{TS}_{2}(\mathrm{M}=\mathrm{La}, \mathrm{Yb} ; \mathrm{T}=\mathrm{Cr}, \mathrm{Nb})[32,81]$.

\begin{tabular}{|c|c|c|c|c|c|c|c|c|c|}
\hline Sample & Direction & $\begin{array}{c}T \\
(\mathbf{K}) \\
\end{array}$ & $\begin{array}{c}\rho \\
(\mu \Omega \cdot m)\end{array}$ & $\begin{array}{c}S \\
\left(\mu V \cdot K^{-1}\right)\end{array}$ & $\begin{array}{c}\mathbf{K}_{\text {total }} \\
\left(\mathbf{W} \cdot \mathbf{K}^{-1} \cdot \mathbf{m}^{-1}\right) \\
\end{array}$ & $\begin{array}{c}\kappa_{\text {lat }} \\
\left(\mathbf{W} \cdot \mathbf{K}^{-1} \cdot \mathbf{m}^{-1}\right) \\
\end{array}$ & $\begin{array}{c}S^{2} / \rho \\
\left(\mu \mathbf{W} \cdot \mathbf{K}^{-2} \cdot \mathbf{m}^{-1}\right) \\
\end{array}$ & $Z T$ & Reference \\
\hline$\left(\mathrm{Yb}_{2} \mathrm{~S}_{2}\right)_{0.62} \mathrm{NbS}_{2}$ & In-plane & 300 & 19.0 & 60 & 0.80 & 0.41 & 200 & 0.1 & [81] \\
\hline$\left(\mathrm{La}_{2} \mathrm{~S}_{2}\right)_{0.62} \mathrm{NbS}_{2}$ & In-plane & 300 & 11.5 & 22 & - & - & 50 & - & [81] \\
\hline \multirow{4}{*}{$(\mathrm{LaS})_{1.14 \mathrm{NbS}_{2}}{ }^{\mathrm{a}}$} & \multirow{2}{*}{ In-plane } & 300 & 7.6 & 37 & 2.50 & 1.50 & 177 & 0.02 & \multirow{4}{*}[32]{} \\
\hline & & 950 & 22.0 & 83 & 2.00 & 0.93 & 316 & 0.15 & \\
\hline & \multirow{2}{*}{ Out-of-plane } & 300 & 13.3 & 25 & 2.04 & 1.48 & 49 & 0.01 & \\
\hline & & 950 & 32.1 & 72 & 1.62 & 0.88 & 162 & 0.09 & \\
\hline \multirow{4}{*}{$(\mathrm{LaS})_{1.14} \mathrm{NbS}_{2}{ }^{\mathrm{b}}$} & \multirow{2}{*}{ In-plane } & 300 & 5.2 & 35 & 4.88 & 3.45 & 233 & 0.02 & \multirow{4}{*}[32]{} \\
\hline & & 950 & 16.9 & 83 & 3.25 & 1.86 & 405 & 0.15 & \\
\hline & \multirow{2}{*}{ Out-of-plane } & 300 & 9.3 & 25 & 1.56 & 0.75 & 70 & 0.01 & \\
\hline & & 950 & 28.5 & 56 & 1.34 & 0.52 & 111 & 0.09 & \\
\hline \multirow{2}{*}{$(\mathrm{LaS})_{1.2} \mathrm{CrS}_{2}{ }^{\mathrm{a}}$} & In-plane & 950 & 207 & -172 & 1.16 & 1.04 & 143 & 0.12 & \multirow{2}{*}[32]{} \\
\hline & Out-of-plane & 950 & 223 & -174 & 1.02 & 0.91 & 137 & 0.13 & \\
\hline \multirow{2}{*}{$(\mathrm{LaS})_{1.2} \mathrm{CrS}_{2}{ }^{b}$} & In-plane & 950 & 171 & -172 & 1.25 & 1.11 & 174 & 0.13 & \multirow{2}{*}[32]{} \\
\hline & Out-of-plane & 950 & 278 & -154 & 0.92 & 0.84 & 84 & 0.08 & \\
\hline
\end{tabular}

a Small grains $(\sim 1 \mu \mathrm{m})$, weak/random orientation of grains; ${ }^{\mathrm{b}}$ Large grains $(>20 \mu \mathrm{m})$, strong orientation of grains perpendicular to the pressing direction.

As seen from Table 2, misfit compounds are highly sensitive to microstructural variations because of the anisotropic nature of their atomic bonds. Therefore, one strategy to enhance $Z T$ is tuning the microstructure. Microstructure control was achieved in $(\mathrm{LaS})_{1+m} \mathrm{TS}_{2}(\mathrm{~T}=\mathrm{Nb}, \mathrm{Cr})$ [32] by varying the sulfurization duration from 6 to $12 \mathrm{~h}$, followed by pressure-assisted sintering to obtain samples with randomly and highly oriented textures. Extended sulfurization (for $12 \mathrm{~h}$ ) resulted in higher carbon content in the samples, which impeded grain growth [91]. On the other hand, the grains in the sample sulfurized for $6 \mathrm{~h}$ grew to $>20 \mu \mathrm{m}$ and self-arranged into a layered structure after sintering (Figure $4 \mathrm{~b}$ ). Large anisotropy was observed in thermoelectric properties for both the systems (Table 2). Both systems show low total thermal conductivity $\kappa_{\text {total }}$, especially in the out-of-plane direction, and the lowest $\kappa_{\text {total }}$ was observed for highly oriented $(\mathrm{LaS})_{1.2} \mathrm{CrS}_{2}\left(\sim 0.92 \mathrm{~W} \cdot \mathrm{K}^{-1} \cdot \mathrm{m}^{-1}\right)$ and $(\mathrm{LaS})_{1.14 \mathrm{NbS}_{2}}\left(\sim 1.34 \mathrm{~W} \cdot \mathrm{K}^{-1} \cdot \mathrm{m}^{-1}\right)$, which mainly results from the very low $\kappa_{\text {lat }} \sim 0.84 \mathrm{~W} \cdot \mathrm{K}^{-1} \cdot \mathrm{m}^{-1}$ and $\sim 0.52 \mathrm{~W} \cdot \mathrm{K}^{-1} \cdot \mathrm{m}^{-1}$, respectively, at $950 \mathrm{~K}$. The low $\kappa_{\text {lat }}$ is attributed to the fact that the interfaces between the host $\mathrm{TS}_{2}$ and guest MS layers act as effective phonon scatterers. Similar to $\rho$ and $\kappa_{\text {lat, }} S$ was found to be highly anisotropic for the highly oriented $\mathrm{NbS}_{2}$ misfit compounds. For instance, the in-plane and out-of-plane $S$ values were $\sim 83 \mu \mathrm{V} \cdot \mathrm{K}^{-1}$ and $\sim 56 \mu \mathrm{V} \cdot \mathrm{K}^{-1}$, respectively, for $(\mathrm{LaS})_{1.14 N b S}$ at $950 \mathrm{~K}$. The anisotropy in $S$ may have originated from the anisotropic band structure. Band-structure calculations showed that strong intralayer energy dispersions $(\sim 1.0 \mathrm{eV})$ occur near the Fermi level, while smaller dispersions of $0.01-0.05 \mathrm{eV}$ occur in the interlayer direction $[79,88]$.

Defects such as the presence of extra bright contrast planes are observed in the HRTEM image (indicated by white arrows) and ED patterns (streaks along the $c$-axis) of the $\mathrm{CrS}_{2}$ system (Figure 8), which exhibits coherent stacking-fault-induced intergrowth of $\mathrm{CrS}_{2}$ layers [32]. With proper 
manipulation, these crystal defects can help improve the thermoelectric properties. These nanoscale defects, along with the phonon scattering at the atomic scale (layer interfaces, dopants, and point defects) and micro scale (microstructure control) make these compounds good candidates for $Z T$ enhancement through all-length-scale hierarchical architecturing $[17,18,20]$.

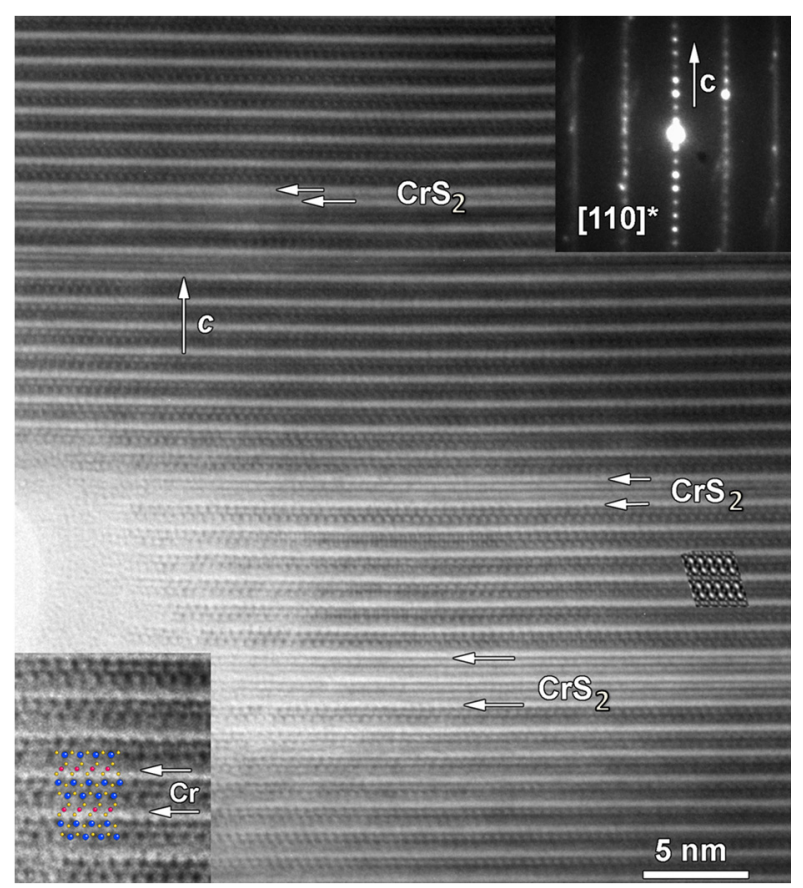

Figure 8. High-resolution transmission electron microscopy (HRTEM) image of (LaS) ${ }_{1.2} \mathrm{CrS}_{2}$ and corresponding electron diffraction pattern. The structural model superimposed on the enlarged HRTEM image is given as inset in the bottom-left corner of the figure. La, Cr, and $\mathrm{S}$ are represented by blue, red, and yellow, respectively. White arrows indicate stacking faults/defects (taken with permission from reference [32]).

The highly oriented texture provided the highest $Z T \sim 0.14$ at $950 \mathrm{~K}$ in $(\mathrm{LaS})_{1.2} \mathrm{CrS}_{2}$, while the sample

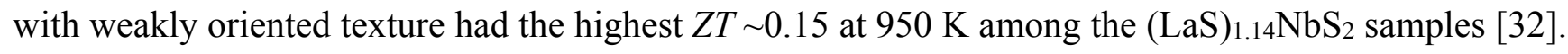
Carrier mobility $(\mu)$ is quite low in these misfit compounds with $\mu \sim 0.5-1.6 \mathrm{~cm}^{2} \cdot \mathrm{V}^{-1} \cdot \mathrm{s}^{-1}$ for the $\mathrm{CrS}_{2}$ system and $\mu \sim 7-11 \mathrm{~cm}^{2} \cdot \mathrm{V}^{-1} \cdot \mathrm{s}^{-1}$ for the $\mathrm{NbS}_{2}$ system at $300 \mathrm{~K}$. The carrier concentrations at $300 \mathrm{~K}$ are $n \sim 3 \times 10^{20} \mathrm{~cm}^{-3}$ for the $\mathrm{CrS}_{2}$ system and $n \sim 1 \times 10^{21} \mathrm{~cm}^{-3}$ for the $\mathrm{NbS}_{2}$ system; these values need to be optimized further for enhancing $S^{2} / \rho$. The $Z T$ can, therefore, be further improved through appropriate doping and substitutions not only to optimize $n$ but also to tune the stacking faults, as reported for the $\mathrm{TiS}_{2}$ misfit system $[64,66]$. These misfit layered sulfides are promising candidates for high-temperature thermoelectric applications as they are environmentally benign, nontoxic, and stable at high temperature; further, they provide tremendous opportunities for enhancing $Z T$.

\section{Homologous Chalcogenides}

A structure of the homologous series is built on the same structural principle with certain module(s) expanding in various dimension(s) by regular increments [92-96]. For example, the crystal structure of the cannizzarite homologous series consists of alternating infinite $\mathrm{PbSe}$ - and $\mathrm{Bi}_{2} \mathrm{Se}_{3}$-type layers $[33,95,97]$, 
as shown in Figures 1c and 9. The two layers are stacked alternately along the $c$-axis, resulting in a three-dimensional structure with varying thicknesses that form different members in the homology. The thermoelectric properties of homologous compounds can be tuned by modifying the size and shape of the structural module(s); therefore, the homologous compounds are good platforms for developing new thermoelectric materials [34,94,98-109].

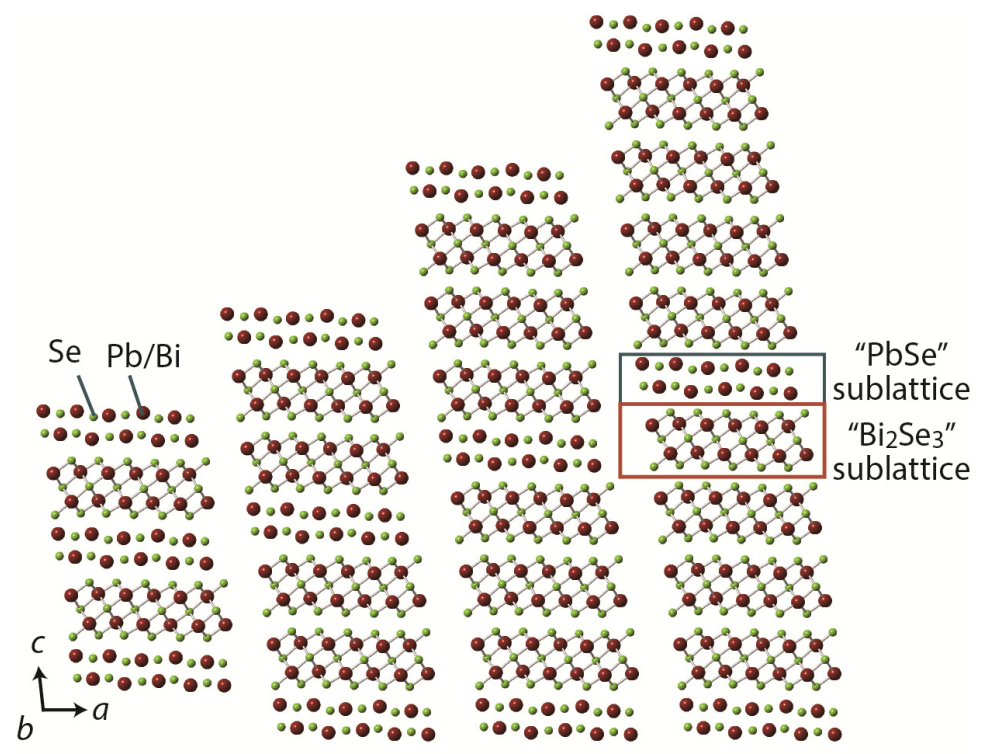

(a) $\mathrm{Pb}_{5} \mathrm{Bi}_{6} \mathrm{Se}_{14}$ (b) $\mathrm{Pb}_{5} \mathrm{Bi}_{12} \mathrm{Se}_{23}$ (c) $\mathrm{Pb}_{5} \mathrm{Bi}_{18} \mathrm{Se}_{32}$ (d) $\mathrm{Pb}_{5} \mathrm{Bi}_{24} \mathrm{Se}_{41}$

Figure 9. Structural evolution in the cannizzarite homologous series $\left[(\mathrm{PbSe})_{5}\right]_{m}\left[\left(\mathrm{Bi}_{2} \mathrm{Se}_{3}\right)_{3}\right]_{n}$ : (a) $\mathrm{Pb}_{5} \mathrm{Bi}_{6} \mathrm{Se}_{14}(m=1, n=1)$; (b) $\mathrm{Pb}_{5} \mathrm{Bi}_{12} \mathrm{Se}_{23}(m=1, n=2)$; (c) $\mathrm{Pb}_{5} \mathrm{Bi}_{18} \mathrm{Se}_{32}(m=1, n=3)$; and (d) $\mathrm{Pb}_{5} \mathrm{Bi}_{24} \mathrm{Se}_{41}(m=1, n=4)[33,95,97]$. The sizes of atoms in this figure are arbitrary.

Figure 10 shows the $\kappa_{\text {lat }}, Z T$, and crystal structure of $\mathrm{CsBi}_{4} \mathrm{Te}_{6}$, a member of the $\mathrm{Cs}_{4}\left[\mathrm{Bi}_{2 n+4} \mathrm{Te}_{3 n+6}\right]$ homologous series [99,102]; $\mathrm{SnBi}_{2} \mathrm{Te}_{4}$, a member of the [SnTe $]_{n}\left[\mathrm{Bi}_{2} \mathrm{Te}_{3}\right]_{m}$ homologous series $[106,107]$; $\mathrm{Pb}_{5} \mathrm{Bi}_{6} \mathrm{Se}_{14}$, a member of the cannizzarite homologous series [34]; $\mathrm{PbBi}_{2} \mathrm{~S}_{4}$, a member of the galenobismuthite homologous series [34]; and $\mathrm{Pb}_{7} \mathrm{Bi}_{4} \mathrm{Se}_{13}$, a member of lillianite homologous series [109]. CsBi4 $\mathrm{Te}_{6}$ and $\mathrm{SnBi}_{2} \mathrm{Te}_{4}$ show $p$-type behavior, while $\mathrm{Pb}_{5} \mathrm{Bi}_{6} \mathrm{Se}_{14}, \mathrm{PbBi}_{2} \mathrm{~S}_{4}$, and $\mathrm{Pb}_{7} \mathrm{Bi}_{4} \mathrm{Se}_{13}$ show $n$-type behavior. The complex crystal structures yield low $\kappa_{\text {lat }}$ in the range of 0.15 to $1.15 \mathrm{~W} \cdot \mathrm{K}^{-1} \cdot \mathrm{m}^{-1}$ over the temperature range of $100 \mathrm{~K}$ to $763 \mathrm{~K}$, leading to high $Z T$. A record-high ZT of $\sim 0.8$ at $225 \mathrm{~K}$ and a high $Z T$ of $\sim 0.9$ at $775 \mathrm{~K}$ were found in $\mathrm{CsBi}_{4} \mathrm{Te}_{6}$ and $\mathrm{Pb}_{7} \mathrm{Bi}_{4} \mathrm{Se}_{13}$, respectively.

As shown in Figure 4c, the scanning electron microscope images of the fractured section of sintered compacts of $\mathrm{Pb}_{5} \mathrm{Bi}_{6} \mathrm{Se}_{14}$ reveal that the crystal grains were preferentially grown in the direction perpendicular to the pressure applied during sintering, forming needle-like grains with a mean length of $\sim 30 \mu \mathrm{m}$. The XRD patterns show that the crystalline $c$-axis is preferentially oriented along the pressing (out-of-plane) direction [34]. Figure 11 shows the temperature dependence of the $S, \rho, \kappa$ total, Klat, and $Z T$ for sintered compacts of the cannizzarite homologous series member $\mathrm{Pb}_{5} \mathrm{Bi}_{6} \mathrm{Se}_{14}$ in the in-plane and out-of-plane directions. The room-temperature carrier concentration of the system is $\sim 4.8 \times 10^{19} \mathrm{~cm}^{-3}$. As in $\mathrm{TiS}_{2}, S$ was observed to be insensitive to the crystal orientation (Figure 11a); for example, at $705 \mathrm{~K}$, the in-plane $S$ value $\left(\sim 210 \mu \mathrm{V} \cdot \mathrm{K}^{-1}\right)$ is in rough agreement with the out-of-plane $S$ value $\left(\sim 230 \mu \mathrm{V} \cdot \mathrm{K}^{-1}\right)$. On the other hand, the interfaces between the PbSe layer and the $\mathrm{Bi}_{2} \mathrm{Se}_{3}$ layer effectively scatter the 


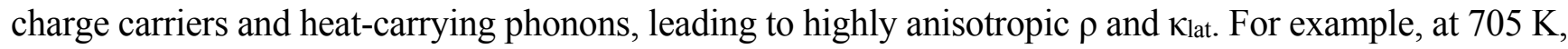
the in-plane $\rho$ value $(\sim 130 \mu \Omega \cdot \mathrm{m})$ is $60 \%$ lower than the out-of-plane $\rho$ value $(\sim 320 \mu \Omega \cdot \mathrm{m})$ (Figure $11 \mathrm{~b}$ ),

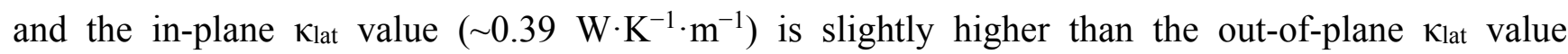
$\left(\sim 0.31 \mathrm{~W} \cdot \mathrm{K}^{-1} \cdot \mathrm{m}^{-1}\right)$ (Figure 11c). The lower $\rho$ in the in-plane direction and the insensitivity of $S$ to crystal orientation results in a higher $S^{2} / \rho$ of $320 \mu \mathrm{W} \cdot \mathrm{K}^{-2} \cdot \mathrm{m}^{-1}$ and higher $Z T$ of 0.46 in the in-plane direction at 705 K (Figure 11d).
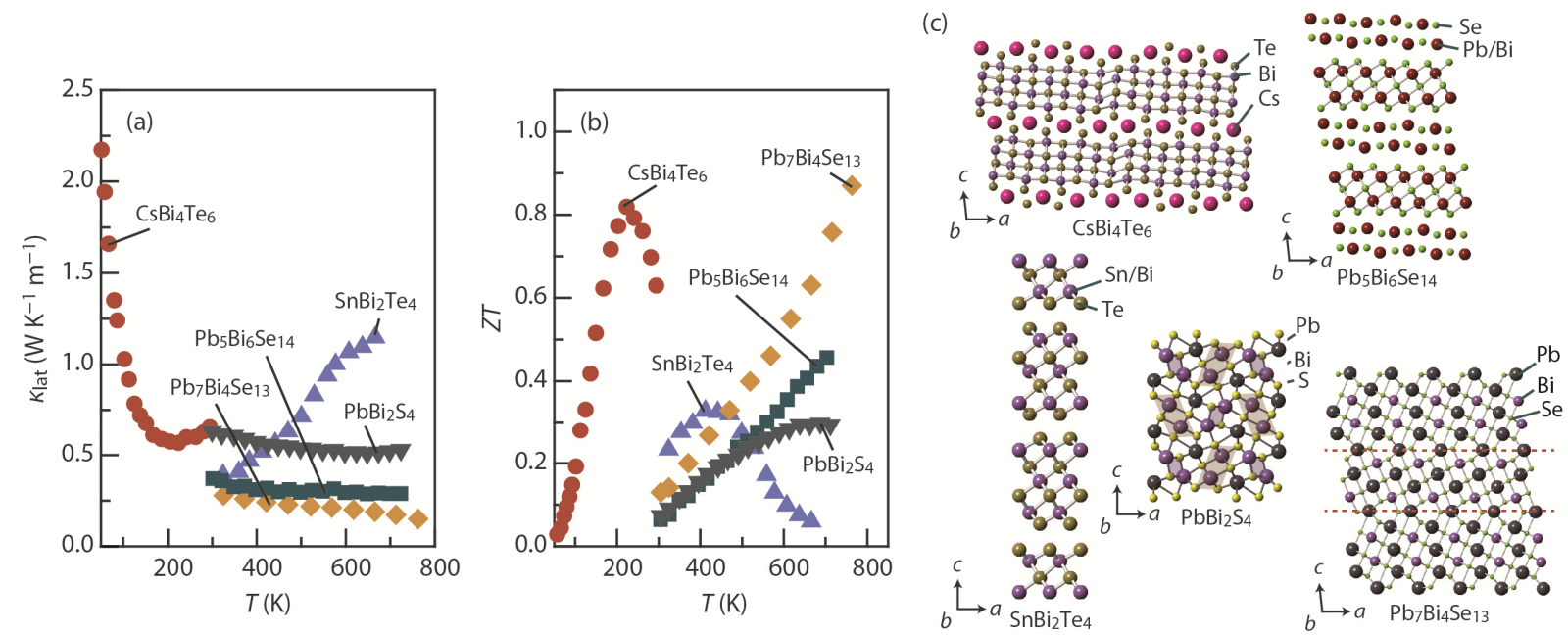

Figure 10. Temperature dependence of the (a) lattice thermal conductivity ( $\kappa_{\text {lat}) \text {; }}$ (b) thermoelectric figure of merit (ZT); and (c) crystal structure of $\mathrm{CsBi}_{4} \mathrm{Te}_{6}$, a member of the $\mathrm{Cs}_{4}\left[\mathrm{Bi}_{2 n+4} \mathrm{Te}_{3 n+6}\right]$ homologous series $[99,102] ; \mathrm{SnBi}_{2} \mathrm{Te}_{4}$, a member of the $[\mathrm{SnTe}]_{n}\left[\mathrm{Bi}_{2} \mathrm{Te}_{3}\right]_{m}$ homologous series [106,107]; $\mathrm{Pb}_{5} \mathrm{Bi}_{6} \mathrm{Se}_{14}$, a member of the cannizzarite homologous series [34]; $\mathrm{PbBi}_{2} \mathrm{~S}_{4}$, a member of the galenobismuthite homologous series [34]; and $\mathrm{Pb}_{7} \mathrm{Bi}_{4} \mathrm{Se}_{13}$, a member of the lillianite homologous series [109].
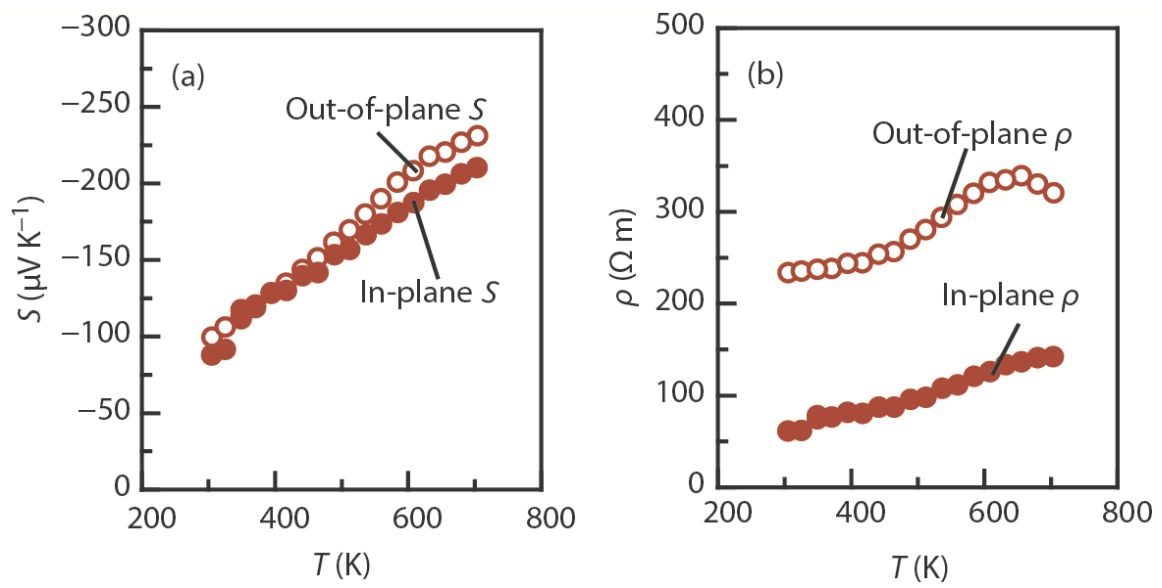

Figure 11. Cont. 

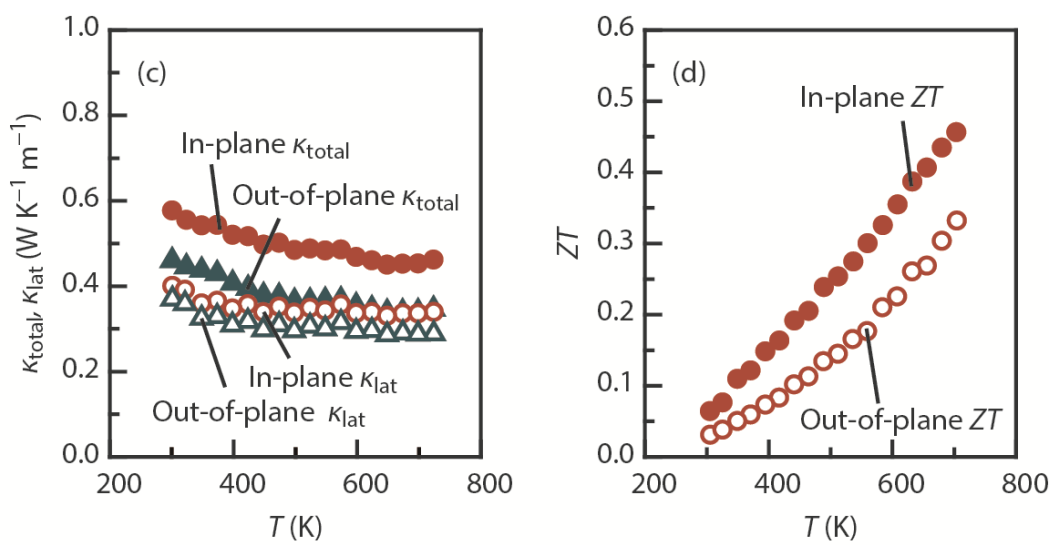

Figure 11. Temperature dependence of the (a) Seebeck coefficient $(S)$, (b) electrical resistivity $(\rho),(\mathbf{c})$ total thermal conductivity ( $\left.\kappa_{\text {total }}\right)$ and lattice thermal conductivity $(\kappa$ lat $)$, and (d) thermoelectric figure of merit $(Z T)$ for sintered compacts of the cannizzarite homologous member $\mathrm{Pb}_{5} \mathrm{Bi}_{6} \mathrm{Se}_{14}$ in the in-plane (ab-plane) and out-of-plane (c-axis) directions [34].

One way to enhance the $Z T$ of homologous compounds is the tuning of carrier concentration $n$ through doping for optimizing $S^{2} / \rho$. Another way is to reduce $\kappa_{\text {lat }}$ further by increasing the complexity of the crystal structure using crystal-structural evolution enabled by the homologous series (Figure 9). Table 3 lists the room-temperature thermoelectric properties of three members of the cannizzarite homologous series, $\mathrm{Pb}_{5} \mathrm{Bi}_{6} \mathrm{Se}_{14}, \mathrm{~Pb}_{5} \mathrm{Bi}_{12} \mathrm{Se}_{23}$, and $\mathrm{Pb}_{5} \mathrm{Bi}_{18} \mathrm{Se}_{32}$ [103]. An important result here is that klat systematically reduces from $0.72 \mathrm{~W} \cdot \mathrm{K}^{-1} \cdot \mathrm{m}^{-1}$ for $\mathrm{Pb}_{5} \mathrm{Bi}_{6} \mathrm{Se}_{14}(m=1, n=1)$ to $0.49 \mathrm{~W} \cdot \mathrm{K}^{-1} \cdot \mathrm{m}^{-1}$ for $\mathrm{Pb}_{5} \mathrm{Bi}_{18} \mathrm{Se}_{32}(m=1, n=3)$, demonstrating the reduction in $\kappa_{\text {lat }}$ through crystal-structural evolution at the atomic scale.

Table 3. Seebeck coefficient $(S)$, electrical resistivity $(\rho)$, carrier concentration $(n)$, carrier mobility $(\mu)$, power factor $\left(S^{2} / \rho\right)$, lattice thermal conductivity $\left(\kappa_{l a t}\right)$, and thermoelectric figure of merit $(Z T)$ at room temperature in three members of the cannizzarite homologous series, $\mathrm{Pb}_{5} \mathrm{Bi}_{6} \mathrm{Se}_{14}, \mathrm{~Pb}_{5} \mathrm{Bi}_{12} \mathrm{Se}_{23}$, and $\mathrm{Pb}_{5} \mathrm{Bi}_{18} \mathrm{Se}_{32}[103]$.

\begin{tabular}{cccccccc}
\hline Sample & $\begin{array}{c}\boldsymbol{S} \\
\left(\boldsymbol{\mu} \mathbf{V} \cdot \mathbf{K}^{-\mathbf{1}}\right)\end{array}$ & $\begin{array}{c}\boldsymbol{\rho} \\
(\boldsymbol{\mu} \boldsymbol{\Omega} \cdot \mathbf{m})\end{array}$ & $\begin{array}{c}\boldsymbol{n} \\
\left(\mathbf{c m}^{-\mathbf{3}}\right)\end{array}$ & $\begin{array}{c}\boldsymbol{\mu} \\
\left(\mathbf{c m}^{\mathbf{2}} \cdot \mathbf{V}^{-\mathbf{1}} \cdot \mathbf{s}^{-\mathbf{1}}\right)\end{array}$ & $\begin{array}{c}\boldsymbol{S}^{2} \mathbf{\rho} \\
\left(\boldsymbol{\mu} \mathbf{W} \cdot \mathbf{K}^{-\mathbf{2}} \cdot \mathbf{m}^{-\mathbf{1}}\right)\end{array}$ & $\begin{array}{c}\text { Klat } \\
\left(\mathbf{W} \cdot \mathbf{K}^{-\mathbf{1}} \cdot \mathbf{m}^{-\mathbf{1}}\right)\end{array}$ & $\boldsymbol{Z T}$ \\
\hline $\mathrm{Pb}_{5} \mathrm{Bi}_{6} \mathrm{Se}_{14}$ & -28 & 22 & $0.86 \times 10^{-20}$ & 33 & 36 & 0.72 & 0.01 \\
$\mathrm{~Pb}_{5} \mathrm{Bi}_{12} \mathrm{Se}_{23}$ & -27 & 27 & $1.15 \times 10^{-20}$ & 20 & 27 & 0.59 & 0.01 \\
$\mathrm{~Pb}_{5} \mathrm{Bi}_{18} \mathrm{Se}_{32}$ & -52 & 39 & $1.19 \times 10^{-20}$ & 14 & 69 & 0.49 & 0.03 \\
\hline
\end{tabular}

\section{Accordion-Like Layered $\operatorname{SnQ}(Q=S, S e)$}

The major strategies for achieving good thermoelectric performance have mostly involved the use of heavy elements (often toxic elements such as $\mathrm{Pb}$ ), nanostructuring (which requires precise control of synthesis procedures) [15-21], and complex unit cells such as skutterudites [22-27] and zintl phases [110]. SnSe, however, possesses a very simple crystal structure with light, earth-abundant elements (Figure 1d) and exhibits an intrinsically ultra-low thermal conductivity [35]. SnSe has a layered orthorhombic crystal structure with zigzag (accordion-like) atomic chains (space group Pnma) below $\sim 750 \mathrm{~K}$ [111]; at $\sim 750 \mathrm{~K}$, it undergoes a phase transition towards its higher-symmetry phase (space group $\mathrm{Cmcm}$ ) [112,113]. SnSe, which has been ignored by the thermoelectric community in the past, 
has attracted tremendous interest after the very recent report by Kanatzidis et al. [35], which demonstrates a record-high $Z T$ of $\sim 2.62$ at $923 \mathrm{~K}$ along the $b$-axis, high $Z T$ of $\sim 2.3$ along the $c$-axis, and moderate $Z T$ of $\sim 0.8$ along the $a$-axis in single-crystal SnSe. The lighter analogous sulfide $\mathrm{SnS}$ has also received attention in the thermoelectric community [114-116].

Figure 12 shows a comparison of the thermoelectric properties of single-crystal [35], polycrystalline [117], and Ag-alloyed SnSe [118]. There are no significant differences observed $S$ between the $a$-, $b$-, and $c$-axis for single-crystal SnSe. $S$ decreases at the transition temperature of $\sim 750 \mathrm{~K}$ but retains a high value (Figure 12a). For example, the $b$-axis $S$ for single crystals decreases from $\sim 570 \mu \mathrm{V} \cdot \mathrm{K}^{-1}$ at $573 \mathrm{~K}$ to $\sim 340 \mu \mathrm{V} \cdot \mathrm{K}^{-1}$ at $823 \mathrm{~K}$. Unlike $S$, a large anisotropy in $\rho$ can be seen for the single crystal, where $\rho$ along the $b$ - and $c$-axis is much smaller than that along the $a$-axis (Figure 12b). This is because the carrier mobilities $\mu \sim 250 \mathrm{~cm}^{2} \cdot \mathrm{V}^{-1} \cdot \mathrm{s}^{-1}$ in the $b$-axis direction and $\mu \sim 130 \mathrm{~cm}^{2} \cdot \mathrm{V}^{-1} \cdot \mathrm{s}^{-1}$ in the $c$-axis direction at $300 \mathrm{~K}$ are higher within the plane of the slab than in the inter-slab direction. The in-plane and out-of-plane $\rho$ of the polycrystalline samples yielded similar observations. The value of $\rho$ dramatically decreases at $\sim 750 \mathrm{~K}$ and consequently increases $S^{2} / \rho$. In the case of single crystals, the $b$-axis $\rho$ decreases from $\sim 2000 \mu \Omega \cdot \mathrm{m}$ at $573 \mathrm{~K}$ to $\sim 120 \mu \Omega \cdot \mathrm{m}$ at $823 \mathrm{~K}$. With $\mathrm{Ag}$ alloying of polycrystalline $\mathrm{SnSe}$, the room-temperature carrier concentration increases from $2 \times 10^{17} \mathrm{~cm}^{-3}$ for a pure system to $9 \times 10^{18} \mathrm{~cm}^{-3}$ for a $7 \% \mathrm{Ag}$ system [118]. The $1 \% \mathrm{Ag}$-alloyed $\mathrm{SnSe}$ system produces the highest $Z T$ of $\sim 0.6$ at $750 \mathrm{~K}$, in contrast to the pure SnSe system, which has a $Z T$ of $\sim 0.3$ at the same temperature and $\sim 0.5$ at $820 \mathrm{~K}$ (Figure $12 \mathrm{~d}$ ).
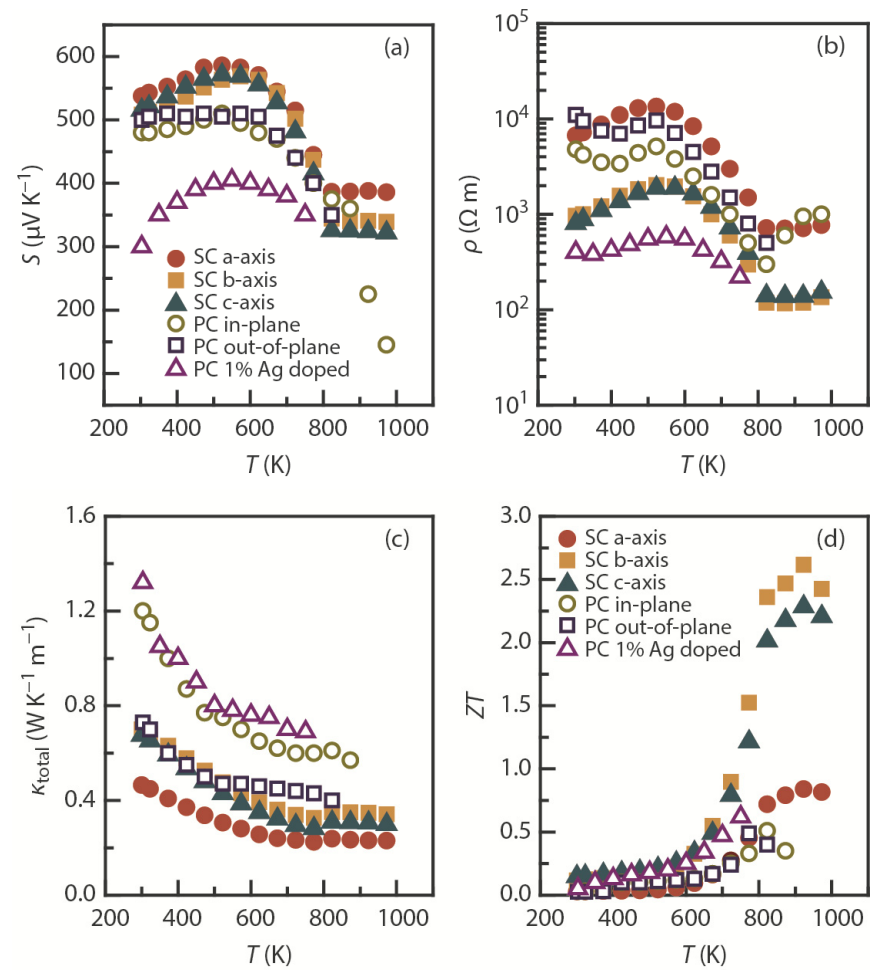

Figure 12. Temperature dependence of the (a) Seebeck coefficient $(S)$; (b) electrical resistivity $(\rho)$; (c) total thermal conductivity $\left(\kappa_{\text {total }}\right)$; and $(\mathbf{d})$ thermoelectric figure of merit $(Z T)$ for single-crystal (SC) SnSe measured along the $a$-, $b$-, and $c$-axis [35], polycrystalline (PC) SnSe in the in-plane (crystalline $b c$-plane) and out-of-plane (crystalline $a$-axis) directions [117], and $1 \% \mathrm{Ag}$-alloyed polycrystalline $\mathrm{SnSe}$ in the in-plane direction [118]. 
The performance of SnSe surpasses that of other materials, especially above the transition temperature of $\sim 750 \mathrm{~K}$, where the single-crystal $\kappa_{\text {lat }}$ less than $0.25 \mathrm{~W} \cdot \mathrm{K}^{-1} \cdot \mathrm{m}^{-1}$ is achieved along all crystallographic axes (Figure 12c) [35]. This value is significantly lower than the $\kappa$ lat obtained for all-length-scale hierarchically architectured PbTe (PbTe-4 mol\% SrTe-2 mol\% Na has Klat $\sim 0.5 \mathrm{~W} \cdot \mathrm{K}^{-1} \cdot \mathrm{m}^{-1}$ and $Z T \sim 2.2$ at $900 \mathrm{~K}$ ) [17] and skutterudites exhibiting rattling (for example, LaFe $\mathrm{CoSb}_{12}$ has $\kappa_{\text {lat }} \sim 1 \mathrm{~W} \cdot \mathrm{K}^{-1} \cdot \mathrm{m}^{-1}$ and $Z T \sim 0.9$ at $\left.750 \mathrm{~K}\right)$ [22].

One would expect the $\kappa_{\text {total }}\left(\kappa_{\text {lat }}\right)$ of polycrystalline samples to be less than that of single-crystal samples because of increased phonon scattering from grain boundaries in polycrystalline samples; however, the opposite is observed for SnSe (Figure 12c). For instance, in-plane $\kappa_{\text {total }}$ values of $\sim 0.6 \mathrm{~W} \cdot \mathrm{K}^{-1} \cdot \mathrm{m}^{-1}$ (at $850 \mathrm{~K}$ ) and $\sim 0.7 \mathrm{~W} \cdot \mathrm{K}^{-1} \cdot \mathrm{m}^{-1}$ (at $750 \mathrm{~K}$ ) were obtained for pure polycrystalline and Ag-alloyed SnSe, respectively. However, very low $\kappa_{\text {total }}$ values of $\sim 0.23 \mathrm{~W} \cdot \mathrm{K}^{-1} \cdot \mathrm{m}^{-1}$ (a-axis), $\sim 0.34 \mathrm{~W} \cdot \mathrm{K}^{-1} \cdot \mathrm{m}^{-1}$ (b-axis), and $\sim 0.29 \mathrm{~W} \cdot \mathrm{K}^{-1} \cdot \mathrm{m}^{-1}$ (c-axis) were obtained for the single-crystal sample at 973 K. Ab initio studies suggest a strong anisotropy between all the crystallographic axes with the conductivity in the $b$-axis direction $\left(\kappa_{\text {lat }} \sim 1.4 \mathrm{~W} \cdot \mathrm{K}^{-1} \cdot \mathrm{m}^{-1}\right)$ higher than that in the $c$-axis direction $\left(\kappa\right.$ lat $\left.\sim 0.7 \mathrm{~W} \cdot \mathrm{K}^{-1} \cdot \mathrm{m}^{-1}\right)$ at $300 \mathrm{~K}[119]$. This theoretical study relates quite well with the polycrystalline samples but differs markedly from the values for single-crystal samples, in which klat values along $b$ and $c$ axis are reported to be similar $\left(\sim 0.7 \mathrm{~W} \cdot \mathrm{K}^{-1} \cdot \mathrm{m}^{-1}\right.$ at $\left.300 \mathrm{~K}\right)$. As data for only two directions (i.e., parallel and perpendicular to the pressing direction) are available for polycrystalline samples, it is difficult to draw conclusions. Furthermore, the room-temperature $\kappa_{\text {total }}$ of the single crystal differs markedly from the earlier reported work on SnSe system [120] and therefore, further verification is warranted. Very recent investigations on Te-substituted SnSe [121] and non-stoichiometric SnSe [118] have indicated that $n$-type conductivity in SnSe is feasible.

The lighter analog SnS is also gaining increased interest, backed up by theoretical work [122,123] supporting the good thermoelectric properties of this compound. SnS also has an accordion-like layered structure and is environmentally compatible and cost-effective. Among the few reports on the thermoelectric properties of $\mathrm{SnS}$ [114-116], the Ag-doped system demonstrates the highest ZT of $\sim 0.6$ at $973 \mathrm{~K}$ [116]. There is a big scope for improvement in ZT through improved doping and an all-length-scale hierarchical architecture approach.

\section{Thermoelectric Minerals}

The thermoelectric minerals tetrahedrites $\left(\mathrm{Cu}_{12} \mathrm{Sb}_{4} \mathrm{~S}_{13}\right)$ and colusites $\left(\mathrm{Cu}_{26} \mathrm{~V}_{2} \mathrm{M}_{6} \mathrm{~S}_{32} ; \mathrm{M}=\mathrm{Ge}, \mathrm{Sn}\right)$ include no layers in their crystal structures. However, the $p$-type $Z T$ demonstrated in these mineral-based sulfide systems is among the highest achieved in Pb-free thermoelectric sulfides (Figure 13) and is therefore worth mentioning [36,37,124-126].

The terms "tetrahedrite" and "colusite" are derived from naturally occurring minerals $(\mathrm{Cu}, \mathrm{Fe}, \mathrm{Ag}, \mathrm{Zn})_{12} \mathrm{Sb}_{4} \mathrm{~S}_{13}$ and $\mathrm{Cu}_{24-26} \mathrm{~V}_{2}(\mathrm{As}, \mathrm{Sn}, \mathrm{Sb})_{6} \mathrm{~S}_{32}$, respectively, which are mainly composed of the earth-abundant and low-toxicity elements $\mathrm{Cu}$ and $\mathrm{S}$. The tetrahedrites possess a cubic structure of $I \overline{4} 3 \mathrm{~m}$ symmetry with $\mathrm{SbS}_{3}$ pyramids, $\mathrm{CuS}_{4}$ tetrahedra, and $\mathrm{CuS}_{3}$ triangles. The colusites crystallize in a cubic structure of $P \overline{4} 3 n$ symmetry with $\mathrm{CuS}_{4}$ tetrahedra and $\mathrm{VS}_{4}$ tetrahedra. 

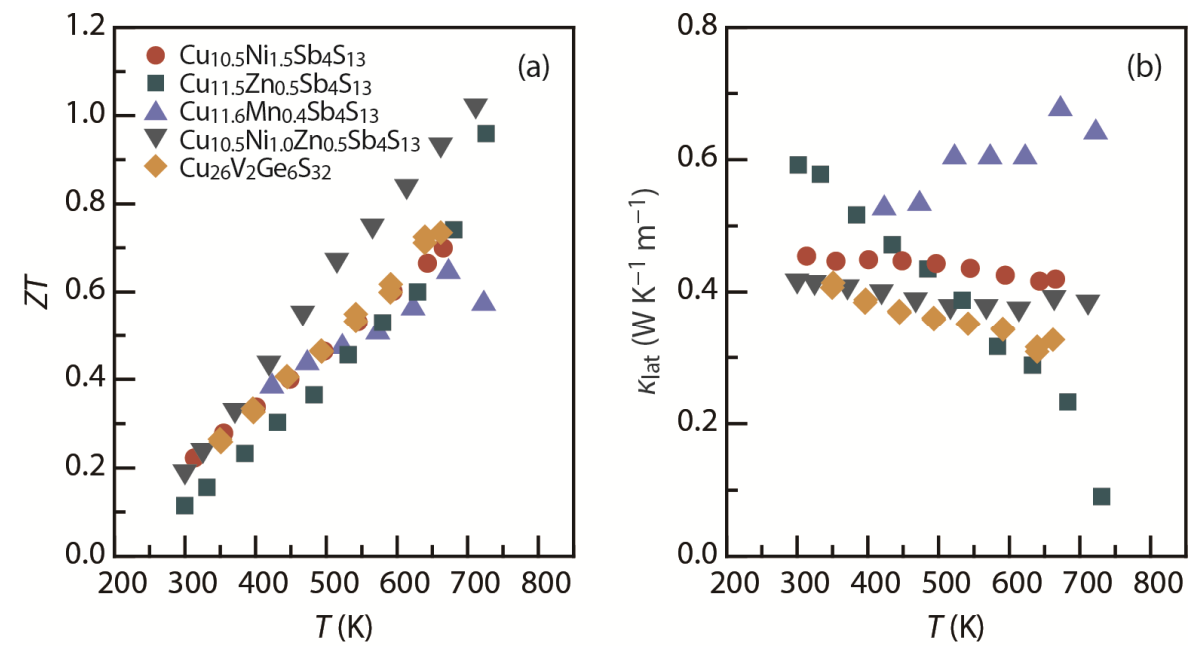

Figure 13. Temperature dependence of (a) thermoelectric figure of merit $(Z T)$ ( $p$-type); and (b) lattice thermal conductivity ( $\kappa$ lat) for the tetrahedrites $\mathrm{Cu}_{10.5} \mathrm{Ni}_{1.5} \mathrm{Sb}_{4} \mathrm{~S}_{13}$ [36], $\mathrm{Cu}_{11.5} \mathrm{Zn}_{0.5} \mathrm{Sb}_{4} \mathrm{~S}_{13}$ [124], $\mathrm{Cu}_{11.6} \mathrm{Mn}_{0.4} \mathrm{Sb}_{4} \mathrm{~S}_{13}$ [125], and $\mathrm{Cu}_{10.5} \mathrm{Ni}_{1.0} \mathrm{Zn}_{0.5} \mathrm{Sb}_{4} \mathrm{~S}_{13}$ [37] and the colusite $\mathrm{Cu}_{26} \mathrm{~V}_{2} \mathrm{Ge}_{6} \mathrm{~S}_{32}[126]$.

In 2012, Suekuni et al. [127] first reported a notable $S^{2} / \rho$ and low אlat at room temperature in tetrahedrite systems. Since then, many efforts have been devoted to enhance the $Z T$ of tetrahedrite systems $[36,37,124,125]$ and to find new mineral-based thermoelectric materials $[126,128]$. As shown in Figure 13, mineral-based sulfide systems show extremely low אlat, resulting in high ZT. In the case of the tetrahedrites, the low $\kappa_{\text {lat }}$ is due to the low-energy vibration of the $\mathrm{Cu}$ atom out of the $\left[\mathrm{CuS}_{3}\right]$ trigonal planar unit, which appears similar to the rattling in skutterudites and clathrates (Figure 1e) [36]. The Klat of both systems ranges from $\sim 0.1 \mathrm{~W} \cdot \mathrm{K}^{-1} \cdot \mathrm{m}^{-1}$ to $\sim 0.7 \mathrm{~W} \cdot \mathrm{K}^{-1} \cdot \mathrm{m}^{-1}$ over the temperature range of 300 to $730 \mathrm{~K}$ (Figure 13b). The value of $S^{2} / \rho$ can be increased by tuning the carrier concentration by substituting $\operatorname{Tr}=\mathrm{Mn}[125,127]$, Fe [124,127], Co [127], Ni [36,37,127], and $\mathrm{Zn} \mathrm{[37,124,127]} \mathrm{at} \mathrm{the} \mathrm{Cu} \mathrm{sites} \mathrm{in}$ $\mathrm{Cu}_{12-x} \operatorname{Tr}_{x} \mathrm{Sb}_{4} \mathrm{~S}_{13}$. For example, the value of $S^{2} / \rho$ at $660 \mathrm{~K}$ was slightly boosted through Ni doping from $1170 \mu \mathrm{W} \cdot \mathrm{K}^{-2} \cdot \mathrm{m}^{-1}$ for $\mathrm{Cu}_{12} \mathrm{Sb}_{4} \mathrm{~S}_{13}$ to $1210 \mu \mathrm{W} \cdot \mathrm{K}^{-2} \cdot \mathrm{m}^{-1}$ for $\mathrm{Cu}_{11.5} \mathrm{Ni}_{0.5} \mathrm{Sb}_{4} \mathrm{~S}_{13}$. A ZT of 1.03 at $723 \mathrm{~K}$ was achieved for $\mathrm{Cu}_{10.5} \mathrm{Ni}_{1.0} \mathrm{Zn}_{0.5} \mathrm{Sb}_{4} \mathrm{~S}_{13}$ (Figure 13a) [37]. Recently, the structural stability and purity of synthetic $\mathrm{Cu}_{12} \mathrm{Sb}_{4} \mathrm{~S}_{13}$ and $\mathrm{Cu}_{10.4} \mathrm{Ni}_{1.6} \mathrm{Sb}_{4} \mathrm{~S}_{13}$ were also reported [129]. These high- $Z T$ sulfide minerals may help realize feasible methods for environment-friendly and cost-effective thermoelectric waste heat recovery.

\section{Conclusions and Insights}

The decoupling of the interdependent thermoelectric properties of a material has always been a challenge in the development of high-efficiency thermoelectric materials. A layered structure not only provides vast opportunities for enhancing the thermoelectric figure of merit $Z T$ through appropriate optimizations at all length scales but also provides methods for individual tuning of thermal and electron transports. Ultra-low lattice thermal conductivities below $0.5 \mathrm{~W} \cdot \mathrm{K}^{-1} \cdot \mathrm{m}^{-1}$ have been obtained through intercalation, crystal-structural evolution, or the formation of stacking faults in layered sulfides. Future work must consider scattering centers on all relevant length scales in a hierarchical manner, i.e., from atomic-scale lattice disorders (layer interfaces, substitution sites, and structural evolution) to nano-scale 
disorders (stacking faults) and microscale grain boundaries (through microtexturing), to achieve the maximum reduction in lattice thermal conductivity. Higher $Z T$ is expected with further work to optimize the carrier concentrations in this new category of materials.

\section{Acknowledgments}

The authors thank Atsushi Yamamoto (AIST), Shinji Hirai (Muroran IT), Toshihiro Kuzuya (Muroran IT), Oleg I. Lebedev (CRISMAT), David Berthebaud (CRISMAT), Duck Young Chung (ANL), Mercouri G. Kanatzidis (Northwestern University and ANL), Mikio Koyano (JAIST), Koichiro Suekuni (Hiroshima University), and Toshiro Takabatake (Hiroshima University) for helpful discussions and fruitful collaborations. Financial support from the Japan-U.S. Cooperation Project for Research and Standardization of Clean Energy Technologies funded by the Ministry of Economy, Trade and Industry (METI) and JSPS KAKENHI Grant Number 25420699 is gratefully acknowledged.

\section{Author Contributions}

Michihiro Ohta designed the work. Priyanka Jood and Michihiro Ohta wrote the manuscript.

\section{Conflicts of Interest}

The authors declare no conflict of interest.

\section{References}

1. Kajikawa, T. Thermoelectric power generation system recovering industrial waste heat. In Thermoelectrics Handbook: Macro to Nano; Rowe, D.M., Ed.; CRC Press: Boca Raton, FL, USA, 2005; pp. 50:1-50:28.

2. Matsubara, K.; Matsuura, M. A Thermoelectric application to vehicles. In Thermoelectrics Handbook: Macro to Nano; Rowe, D.M., Ed.; CRC Press: Boca Raton, FL, USA, 2005; pp. 52:1-52:11.

3. Bell, L.E. Cooling, heating, generating power, and recovering waste heat with thermoelectric systems. Science 2008, 321, 1457-1461.

4. Crane, D.T.; LaGrandeur, J.W. Progress report on BSST-led US department of energy automotive waste heat recovery program. J. Electron. Mater. 2010, 39, 2142-2148.

5. Yang, J.; Stabler, F.R. Automotive applications of thermoelectric materials. In Thermoelectrics and Its Energy Harvesting: Modules, Systems, and Applications in Thermoelectrics; Rowe, D.M., Ed.; CRC Press: Boca Raton, FL, USA, 2012; pp. 25:1-25:15.

6. Slack, G.A. New materials and performance limits for thermoelectric cooling. In CRC Handbook of Thermoelectrics; Rowe, D.M., Ed.; CRC Press: Boca Raton, FL, USA, 1995; pp. 407-440.

7. Terasaki, I.; Sasago, Y.; Uchinokura, K. Large thermoelectric power in $\mathrm{NaCo}_{2} \mathrm{O}_{4}$ single crystals. Phys. Rev. B 1997, 56, R12685-R12687.

8. Masset, A.C.; Michel, C.; Maignan, A.; Hervieu, M.; Toulemonde, O.; Studer, F.; Raveau, B.; Hejtmanek, J. Misfit-layered cobaltite with an anisotropic giant magnetoresistance: $\mathrm{Ca}_{3} \mathrm{Co}_{4} \mathrm{O}_{9}$. Phys. Rev. B 2000, 62, 166-175. 
9. Funahashi, R.; Matsubara, I.; Ikuta, H.; Takeuchi, T.; Mizutani, U.; Sodeoka, S. An oxide single crystal with high thermoelectric performance in air. Jpn. J. Appl. Phys. 2000, 39, L1127-L1129.

10. Koumoto, K.; Terasaki, I.; Kajitani, T.; Ohtaki, M.; Funahashi, R. Oxide thermoelectrics. In Thermoelectrics Handbook: Macro to Nano; Rowe, D.M., Ed.; CRC Press: Boca Raton, FL, USA, 2005; pp. 35:1-35:15.

11. Koumoto, K.; Terasaki, I.; Funahashi, R. Complex oxide materials for potential thermoelectric applications. MRS Bull. 2006, 31, 206-210.

12. Koumoto, K.; Wang, Y.F.; Zhang, R.Z.; Kosuga, A.; Funahashi, R. Oxide thermoelectric materials: A nanostructuring approach. Annu. Rev. Mater. Res. 2010, 40, 363-394.

13. Koumoto, K.; Funahashi, R.; Guilmeau, E.; Miyazaki, Y.; Weidenkaff, A.; Wang, Y.F.; Wan, C.L. Thermoelectric ceramics for energy harvesting. J. Am. Ceram. Soc. 2013, 96, 1-23.

14. Hébert, S.; Kobayashi, W.; Muguerra, H.; Bréard, Y.; Raghavendra, N.; Gascoin, F.; Guilmeau, E.; Maignan, A. From oxides to selenides and sulfides: The richness of the $\mathrm{CdI}_{2}$ type crystallographic structure for thermoelectric properties. Phys. Status Solidi A 2013, 210, 69-81.

15. Biswas, K.; He, J.Q.; Zhang, Q.C.; Wang, G.Y.; Uher, C.; Dravid, V.P.; Kanatzidis, M.G. Strained endotaxial nanostructures with high thermoelectric figure of merit. Nat. Chem. 2011, 3, 160-166.

16. Ohta, M.; Biswas, K.; Lo, S.H.; He, J.Q.; Chung, D.Y.; Dravid, V.P.; Kanatzidis, M.G. Enhancement of thermoelectric figure of merit by the insertion of MgTe nanostructures in $p$-type PbTe doped with $\mathrm{Na}_{2} \mathrm{Te}$. Adv. Energy Mater. 2012, 2, 1117-1123.

17. Biswas, K.; He, J.Q.; Blum, I.D.; Wu, C.I.; Hogan, T.P.; Seidman, D.N.; Dravid, V.P.; Kanatzidis, M.G. High-performance bulk thermoelectrics with all-scale hierarchical architectures. Nature 2012, 489, 414-418.

18. He, J.Q.; Kanatzidis, M.G.; Dravid, V.P. High performance bulk thermoelectrics via a panoscopic approach. Mater. Today 2013, 5, 166-176.

19. Zhao, L.D.; Wu, H.J.; Hao, S.Q.; Wu, C.I.; Zhou, X.Y.; Biswas, K.; He, J.Q.; Hogan, T.P.; Uher, C.; Wolverton, C.; et al. All-scale hierarchical thermoelectrics: MgTe in PbTe facilitates valence band convergence and suppresses bipolar thermal transport for high performance. Energy Environ. Sci. 2013, 6, 3346-3355.

20. Zhao, L.D.; Dravid, V.P.; Kanatzidis, M.G. The panoscopic approach to high performance thermoelectrics. Energy Environ. Sci. 2014, 7, 251-268.

21. Wu, H.J.; Zhao, L.D.; Zheng, F.S.; Wu, D.; Pei, Y.L.; Tong, X.; Kanatzidis, M.G.; He, J.Q. Broad temperature plateau for thermoelectric figure of merit $Z T>2$ in phase-separated $\mathrm{PbTe}_{0.7} \mathrm{~S}_{0.3}$. Nat. Commun. 2014, 5, 4515:1-4515:9.

22. Sales, B.C.; Mandrus, D.; Williams, R.K. Filled skutterudite antimonides: A new class of thermoelectric materials. Science 1996, 272, 1325-1328.

23. Nolas, G.S.; Cohn, J.L.; Slack, G.A.; Schujman, S.B. Semiconducting Ge clathrates: Promising candidates for thermoelectric applications. Appl. Phys. Lett. 1998, 73, 178-180.

24. Nolas, G.S.; Morelli, D.T.; Tritt, T.M. Skutterudites: A phonon-glass-electron crystal approach to advanced thermoelectric energy conversion applications. Annu. Rev. Mater. Sci. 1999, 29, 89-116.

25. Guo, J.Q.; Geng, H.Y.; Ochi, T.; Suzuki, S.; Kikuchi, M.; Yamaguchi, Y.; Ito, S. Development of skutterudite thermoelectric materials and modules. J. Electron. Mater. 2012, 41, 1036-1042. 
26. Takabatake, T. Nano-cage structured materials: Clathrates. In Thermoelectric Nanomaterials: Materials Design and Applications; Koumoto, K., Mori, T., Eds.; Springer: Berlin, Germany, 2013; pp. 33-49.

27. Rogl, G.; Grytsiv, A.; Rogl, P.; Peranio, N.; Bauer, E.; Zehetbauer, M.; Eibl, O. n-type skutterudites $(\mathrm{R}, \mathrm{Ba}, \mathrm{Yb})_{y} \mathrm{Co}_{4} \mathrm{Sb}_{12}(\mathrm{R}=\mathrm{Sr}, \mathrm{La}, \mathrm{Mm}, \mathrm{DD}, \mathrm{SrMm}, \mathrm{SrDD})$ approaching $Z T \approx 2.0$. Acta Mater. 2014, $63,30-43$.

28. Salvador, J.R.; Cho, J.Y.; Ye, Z.; Moczygemba, J.E.; Thompson, A.J.; Sharp, J.W.; Koenig, J.D.; Maloney, R.; Thompson, T.; Sakamoto, J.; et al. Conversion efficiency of skutterudite-based thermoelectric modules. Phys. Chem. Chem. Phys. 2014, 16, 12510-12520.

29. Ohta, M.; Satoh, S.; Kuzuya, T.; Hirai, S.; Kunii, M.; Yamamoto, A. Thermoelectric properties of $\mathrm{Ti}_{1+x} \mathrm{~S}_{2}$ prepared by $\mathrm{CS}_{2}$ sulfurization. Acta Mater. 2012, 60, 7232-7240.

30. Beaumale, M.; Barbier, T.; Bréard, Y.; Guelou, G.; Powell, A.V.; Vaqueiro, P.; Guilmeau, E. Electron doping and phonon scattering in $\mathrm{Ti}_{1+x} \mathrm{~S}_{2}$ thermoelectric compounds. Acta Mater. 2014, $78,86-92$.

31. Meerschaut, A.; Rabu, P.; Rouxel, J. Preparation and characterization of new mixed sandwiched layered compounds $L n_{32} \mathrm{Nb}_{28} \mathrm{~S}_{88}(L n=\mathrm{La}, \mathrm{Ce})$. J. Solid State Chem. 1989, 78, 35-45.

32. Jood, P.; Ohta, M.; Nishiate, H.; Yamamoto, A.; Lebedev, O.I.; Berthebaud, D.; Suekuni, K.; Kunii, M. Microstructural control and thermoelectric properties of misfit layered sulfides $(\mathrm{LaS})_{1+m} \mathrm{TS}_{2}(\mathrm{~T}=\mathrm{Cr}, \mathrm{Nb})$ : The natural superlattice systems. Chem. Mater. 2014, 26, 2684-2692.

33. Zhang, Y.G.; Wilkinson, A.P.; Lee, P.L.; Shastri, S.D.; Shu, D.; Chung, D.Y.; Kanatzidis, M.G. Determining metal ion distributions using resonant scattering at very high-energy $K$-edges: $\mathrm{Bi} / \mathrm{Pb}$ in $\mathrm{Pb}_{5} \mathrm{Bi}_{6} \mathrm{Se}_{14}$. J. Appl. Crystallogr. 2005, 38, 433-441.

34. Ohta, M.; Chung, D.Y.; Kunii, M.; Kanatzidis, M.G. Low lattice thermal conductivity in $\mathrm{Pb}_{5} \mathrm{Bi}_{6} \mathrm{Se}_{14}, \mathrm{~Pb}_{3} \mathrm{Bi}_{2} \mathrm{~S}_{6}$, and $\mathrm{PbBi}_{2} \mathrm{~S}_{4}$ : Promising thermoelectric materials in the cannizzarite, lillianite, and galenobismuthite homologous series. J. Mater. Chem. A 2014, 2, 20048-20058.

35. Zhao, L.D.; Lo, S.H.; Zhang, Y.S.; Sun, H.; Tan, G.J.; Uher, C.; Wolverton, C.; Dravid, V.P.; Kanatzidis, M.G. Ultralow thermal conductivity and high thermoelectric figure of merit in SnSe crystals. Nature 2014, 508, 373-377.

36. Suekuni, K.; Tsuruta, K.; Kunii, M.; Nishiate, H.; Nishibori, E.; Maki, S.; Ohta, M.; Yamamoto, A.; Koyano, M. High-performance thermoelectric mineral $\mathrm{Cu}_{12-} \mathrm{Ni}_{x} \mathrm{Sb}_{4} \mathrm{~S}_{13}$ tetrahedrite. J. Appl. Phys. 2013, 113, 043712:1-043712:5.

37. Lu, X.; Morelli, D.T.; Xia, Y.; Ozolins, V. Increasing the thermoelectric figure of merit of tetrahedrites by Co-doping with nickel and zinc. Chem. Mater. 2015, 27, 408-413.

38. Rimmington, H.P.B.; Balchin, A.A. The growth by iodine vapour transport techniques and the crystal structures of layer compounds in the series $\mathrm{TiS}_{x} \mathrm{Se}_{2}-x, \mathrm{TiS}_{x} \mathrm{Te}_{2-x}, \mathrm{TiSe}_{x} \mathrm{Te}_{2}-x$. J. Cryst. Growth. 1974, 21, 171-181.

39. Han, S.H.; Cook, B.A. An experimental search for high ZT semiconductors: A survey of the preparation and properties of several alloy systems. AIP Conf. Proc. 1995, 316, 66-70.

40. Imai, H.; Shimakawa, Y.; Kubo, Y. Large thermoelectric power factor in TiS2 crystal with nearly stoichiometric composition. Phys. Rev. B 2001, 64, 241104(R):1-241104(R):4.

41. Abbott, E.E.; Kolis, J.W.; Lowhorn, N.D.; Sams, W.; Rao, A.; Tritt, T.M. Thermoelectric properties of doped titanium disulfides. Appl. Phys. Lett. 2006, 88, 262106:1-262106:3. 
42. Wan, C.L.; Wang, Y.F.; Wang, N.; Koumoto, K. Low-thermal-conductivity $(M \mathrm{~S})_{1+x}\left(\mathrm{TiS}_{2}\right)_{2}$ $(M=\mathrm{Pb}, \mathrm{Bi}, \mathrm{Sn})$ misfit layer compounds for bulk thermoelectric materials. Materials 2010, 3, 2606-2617.

43. Wan, C.L.; Wang, Y.F.; Wang, N.; Norimatsu, W.; Kusunoki, M.; Koumoto, K. Intercalation: Building a natural superlattice for better thermoelectric performance in layered chalcogenides. J. Electron. Mater. 2011, 40, 1271-1280.

44. Guilmeau, E.; Bréard, Y.; Maignan, A. Transport and thermoelectric properties in Copper intercalated TiS2 chalcogenide. Appl. Phys. Lett. 2011, 99, 052107:1-052107:3.

45. Gascoin, F.; Raghavendra, N.; Guilmeau, E.; Bréard, Y. $\mathrm{CdI}_{2}$ structure type as potential thermoelectric materials: Synthesis and high temperature thermoelectric properties of the solid solution $\mathrm{TiS}_{x} \mathrm{Se}_{2-x}$. J. Alloy. Compd. 2012, 521, 121-125.

46. Beaumale, M.; Barbier, T.; Bréard, Y.; Hébert, S.; Kinemuchi, Y.; Guilmeau, E. Thermoelectric properties in the series $\mathrm{Ti}_{1-x} \mathrm{Ta}_{x} \mathrm{~S}_{2}$. J. Appl. Phys. 2014, 115, 043704:1-043704:7.

47. Beaumale, M.; Barbier, T.; Bréard, Y.; Raveau, B.; Kinemuchi, Y.; Funahashi, R.; Guilmeau, E. Mass fluctuation effect in $\mathrm{Ti}_{1-x} \mathrm{Nb}_{x} \mathrm{~S}_{2}$ bulk compounds. J. Electron. Mater. 2014, 43, 1590-1596.

48. Henderson, J.R.; Muramoto, M.; Loh, E.; Gruber, J.B. Electronic structure of rare-earth sesquisulfide crystals. J. Chem. Phys. 1967, 47, 3347-3356.

49. Toide, T.; Utsunomiya, T.; Sato, M.; Hoshino, Y.; Hatano, T.; Akimoto, Y. Preparation of lanthanum sulfides using carbon disulfide as sulfurization agent and the change of these sulfides on heating in air. Bull. Tokyo Inst. Technol. 1973, 117, 41-48.

50. Guittard, M.; Flahaut, J. Preparation of rare earth sulfides and selenides. In Synthesis of Lanthanide and Actinide Compounds (Topics in f-Element Chemistry, Volume 2); Meyer, G., Morss, L.R., Eds.; Kluwer Academic: Dordrecht, The Netherlands, 1991; pp. 321-352.

51. Hirai, S.; Shimakage, K.; Saitou, Y.; Nishimura, T.; Uemura, Y.; Mitomo, M.; Brewer, L. Synthesis and sintering of cerium(III) sulfide powders. J. Am. Ceram. Soc. 1998, 81, 145-151.

52. Hirai, S.; Suzuki, K.; Shimakage, K.; Nishimura, T.; Uemura, Y.; Mitomo, M. Preparations of $\gamma-\operatorname{Pr}_{2} \mathrm{~S}_{3}$ and $\gamma-\mathrm{Nd}_{2} \mathrm{~S}_{3}$ powders by sulfurization of $\operatorname{Pr}_{6} \mathrm{O}_{11}$ and $\mathrm{Nd}_{2} \mathrm{O}_{3}$ powders using $\mathrm{CS}_{2}$ gas, and their sintering. J. Jpn. Inst. Metals 2003, 67, 15-21.

53. Miyazaki, Y.; Ogawa, H.; Kajitani, T. Preparation and thermoelectric properties of misfit layered sulfide [Yb $\left.1.90 \mathrm{~S}_{2}\right] 0.62 \mathrm{NbS}_{2}$. Jpn. J. Appl. Phys. 2004, 43, L1202-L1204.

54. Barin, I.; Knacke, O. Thermochemical Properties of Inorganic Substances; Springer-Verlag: Berlin, Germany, 1973.

55. Barin, I.; Knacke, O.; Kubaschewski, O. Thermochemical Properties of Inorganic Substances: Supplement; Springer-Verlag: Berlin, Germany, 1977.

56. Aoki, T.; Wan, C.L.; Ishiguro, H.; Morimitsu, H.; Koumoto, K. Evaluation of layered TiS2-based thermoelectric elements fabricated by a centrifugal heating technique. J. Ceram. Soc. Jpn. 2011, $119,382-385$.

57. Li, D.; Qin, X.Y.; Zhang, J.; Wang, L.; Li, H.J. Enhanced thermoelectric properties of bismuth intercalated compounds $\mathrm{Bi}_{x} \mathrm{TiS}_{2}$. Solid State Commun. 2005, 135, 237-240.

58. Li, D.; Qin, X.Y.; Zhang, J.; Li, H.J. Enhanced thermoelectric properties of neodymium intercalated compounds $\mathrm{Nd}_{x} \mathrm{TiS}_{2}$. Phys. Lett. A 2006, 348, 379-385. 
59. Li, D.; Qin, X.Y.; Zhang, J. Improved thermoelectric properties of gadolinium intercalated compounds $\mathrm{Gd}_{x} \mathrm{TiS}_{2}$ at the temperatures from 5 to 310 K. J. Mater. Res. 2006, 21, 480-483.

60. Zhang, J.; Qin, X.Y.; Li, D.; Dong, H.Z. The electrical and thermal conductivity and thermopower of nickel doped compounds $\left(\mathrm{Ni}_{x} \mathrm{Ti}_{1-x}\right)_{1+y} \mathrm{~S}_{2}$ at low temperatures. J. Phys. D Appl. Phys. 2006, 39, $1230-1236$.

61. Qin, X.Y.; Zhang, J.; Li, D.; Dong, H.Z.; Wang, L. The effect of Mg substitution for Ti on transport and thermoelectric properties of TiS 2. J. Appl. Phys. 2007, 102, 073703:1-073703:7.

62. Zhang, J.; Qin, X.Y.; Li, D.; Xin, H.X.; Pan, L.; Zhang, K.X. The transport and thermoelectric properties of $\mathrm{Cd}$ doped compounds $\left(\mathrm{Cd}_{x} \mathrm{Ti}_{1-x}\right)_{1+y} \mathrm{~S}_{2}$. J. Alloy. Compd. 2009, 479, 816-820.

63. Zhang, J.; Qin, X.Y.; Xin, H.X.; Li, D.; Song, C.J. Thermoelectric properties of Co-doped TiS2. J. Electron. Mater. 2011, 40, 980-986.

64. Wan, C.L.; Wang, Y.F.; Norimatsu, W.; Kusunoki, M.; Koumoto, K. Nanoscale stacking faults induced low thermal conductivity in thermoelectric layered metal sulfides. Appl. Phys. Lett. 2012, 100, 101913:1-101913:4.

65. Putri, Y.E.; Wan, C.L.; Wang, Y.F.; Norimatsu, W.; Kusunoki, M.; Koumoto, K. Effects of alkaline earth doping on the thermoelectric properties of misfit layer sulfides. Scr. Mater. 2012, 66, 895-898.

66. Putri, Y.E.; Wan, C.L.; Dang, F.; Mori, T.; Ozawa, Y.; Norimatsu, W.; Kusunoki, M.; Koumoto, K. Effects of transition metal substitution on the thermoelectric properties of metallic $(\mathrm{BiS})_{1.2}\left(\mathrm{TiS}_{2}\right)_{2}$ misfit layer sulfide. J. Electron. Mater. 2014, 43, 1870-1874.

67. Takeuchi, S.; Katsuta, H. Characteristics of nonstoichiometry and lattice defects of the $\mathrm{TiS}_{2}$ phase. J. Jpn. Inst. Metals 1970, 34, 758-763.

68. Thompson, A.H.; Gamble, F.R.; Symon, C.R. The verification of the existence of TiS 2. Mater. Res. Bull. 1975, 10, 915-919.

69. Murray, J.L. The S-Ti (Sulfur-Titanium) system. J. Phase Equilib. 1986, 7, 156-163.

70. Kobayashi, H.; Sakashita, K.; Sato, M.; Nozue, T.; Suzuki, T.; Kamimura, T. Electronic specific heat of $\mathrm{Ti}_{1+x} \mathrm{~S}_{2}(0<x<0.1)$. Physica $B$ 1997, 237-238, 169-171.

71. Cutler, M.; Leavy, J.F.; Fitzpatrick, R.L. Electronic transport in semimetallic cerium sulfide. Phys. Rev. 1964, 133, A1143-A1152.

72. Snyder, G.J.; Tobere, E.S. Complex thermoelectric materials. Nat. Mater. 2008, 7, 105-114.

73. May, A.F.; Fleurial, J.-P.; Snyder, G.J. Thermoelectric performance of lanthanum telluride produced via mechanical alloying. Phys. Rev. B 2008, 78, 125205:1-125205:12.

74. Logothetis, E.M.; Kaiser, W.J.; Kukkonen, C.A.; Faile, S.P.; Colella, R.; Gambold, J. Transport properties and the semiconducting nature of TiS2. Physica B+C 1980, 99, 193-198.

75. Kukkonen, C.A.; Kaiser, W.J.; Logothetis, E.M.; Blumenstock, B.J.; Schroeder, P.A.; Faile, S.P.; Colella, R.; Gambold, J. Transport and optical properties of $\mathrm{Ti}_{1+x} \mathrm{~S}_{2}$. Phys. Rev. B 1981, 24, 1691-1709.

76. Koyano, M.; Negishi, H.; Ueda, Y.; Sasaki, M.; Inoue, M. Electrical resistivity and thermoelectric power of intercalation compounds $\mathrm{M}_{x} \mathrm{TiS}_{2}(\mathrm{M}=\mathrm{Mn}, \mathrm{Fe}, \mathrm{Co}$, and Ni). Phys. Status Solidi B 1986, 138, 357-363.

77. Amara, A.; Frongillo, Y.; Aubin, M.J.; Jandl, S.; Lopez-Castillo, J.M.; Jay-Gerin, J.-P. Thermoelectric power of TiS 2 . Phys. Rev. B 1987, 36, 6415-6419. 
78. Wiegers, G.A. Misfit layer compounds: Structures and physical properties. Prog. Solid State Chem. 1996, 24, 1-139.

79. Van Smaalen, S. Superspace-group approach to the modulated structure of the inorganic misfit layer compound (LaS) ${ }_{1.14} \mathrm{NbS}_{2}$. J. Phys. Condens. Matter 1991, 3, 1247-1263.

80. Wiegers, G.A.; Meetsma, A.; Haange, R.J.; van Smaalen, S.; de Boer, J.L.; Meerschaut, A.;

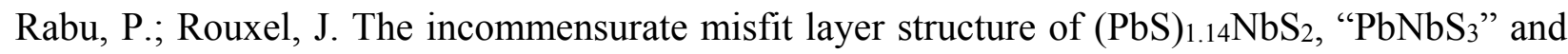

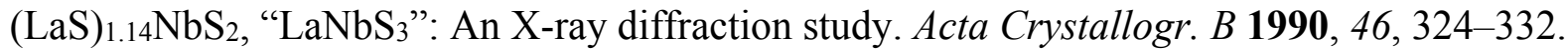

81. Miyazaki, Y.; Ogawa, H.; Nakajo, T.; Kikuchii, Y.; Hayashi, K. Crystal structure and thermoelectric properties of misfit-layered sulfides $\left[\mathrm{Ln}_{2} \mathrm{~S}_{2}\right]_{p} \mathrm{NbS}_{2}(\mathrm{Ln}=$ Lanthanides). J. Electron. Mater. 2013, 42, 1335-1339.

82. Terashima, T.; Kojima, N. Electrical transport properties of incommensurate layer compounds $(\mathrm{RES})_{x} \mathrm{NbS}_{2}(\mathrm{RE}=$ rare-earth metals; $x=1.2,0.6)$. J. Phys. Soc. Jpn. 1994, 63, 658-673.

83. Suzuki, K.; Enoki, T.; Imaeda, K. Synthesis, characterization and physical properties of incommensurate layered compounds/(RES) $)_{x} \mathrm{TaS}_{2}(\mathrm{RE}=$ rare earth metal). Solid State Commun. 1991, 78, 73-77.

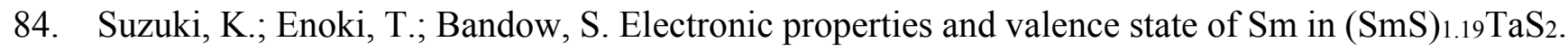
Phys. Rev. B 1993, 48, 11077-11085.

85. Cho, N.; Kikkawa, S.; Kanamaru, F.; Takeda, Y.; Yamamoto, O.; Kido, H.; Hoshikawa, T. Crystal structural, electric and magnetic studies on the misfit layer compounds "LnMS3" ( $\mathrm{Ln}=$ rare-earth metal; M = Ti, V, Cr). Solid State Ion. 1993, 63-65, 696-701.

86. Kato, K.; Kawada, I.; Takahashi, T. Die Kristallstruktur von LaCrS3. Acta Crystallogr. B 1977, 33, 3437-3443.

87. Wiegers, G.A.; Meerschaut, A. Structures of misfit layer compounds $(\mathrm{MS})_{n} \mathrm{TS}_{2}(\mathrm{M}=\mathrm{Sn}, \mathrm{Pb}, \mathrm{Bi}$, rare earth metals; $\mathrm{T}=\mathrm{Nb}, \mathrm{Ta}, \mathrm{Ti}, \mathrm{V}, \mathrm{Cr} ; 1.08<n<1.23)$. J. Alloy. Compd. 1992, 178, 351-368.

88. Fang, C.M.; van Smaalen, S.; Wiegers, G.A.; Haas, C.; de Groot, R.A. Electronic structure of the misfit layer compound $(\mathrm{LaS})_{1.14} \mathrm{NbS}_{2}$ : Band-structure calculations and photoelectron spectra. J. Phys. Condens. Matter 1996, 8, 5367-5382.

89. Fang, C.M.; Ettema, A.R.H.; Haas, C.; Wiegers, G.A.; van Leuken, H.; de Groot, R.A. Electronic structure of the misfit-layer compound $(\mathrm{SnS})_{1.17} \mathrm{NbS}_{2}$ deduced from band-structure calculations and photoelectron spectra. Phys. Rev. B 1995, 52, 2336-2347.

90. Fang, C.M.; de Groot, R.A.; Wiegers, G.A.; Haas, C. Electronic structure of the misfit layer compound $(\mathrm{SnS})_{1.20} \mathrm{TiS}_{2}$ : Band structure calculations and photoelectron spectra. J. Phys. Condens. Matter 1996, 8, 1663-1676.

91. Ohta, M.; Hirai, S.; Ma, Z.; Nishimura, T.; Uemura, Y.; Shimakage, K. Phase transformation and microstructures of $\mathrm{Ln}_{2} \mathrm{~S}_{3}(\mathrm{Ln}=\mathrm{La}, \mathrm{Sm})$ with different impurities content of oxygen and carbon. J. Alloy. Compd. 2006, 408-412, 551-555.

92. Makovicky, E. The building principles and classification of bismuth-lead sulphosalts and related compounds. Fortschr. Mineral. 1981, 59, 137-190.

93. Mrotzek, A.; Kanatzidis, M.G. "Design" in solid-state chemistry based on phase homologies. The concept of structural evolution and the new megaseries $\mathrm{A}_{m}\left[\mathrm{M}_{1+l} \mathrm{Se}_{2+l}\right]_{2 m}\left[\mathrm{M}_{2 l+n} \mathrm{Se}_{2+3 l+n}\right]$. Acc. Chem. Res. 2003, 36, 111-119. 
94. Kanatzidis, M.G. New bulk materials for thermoelectric applications: Synthetic strategies based on phase homologies. In Chemistry, Physics, and Materials Science of Thermoelectric Materials; Kanatzidis, M.G., Mahanti, S.D., Hogan, T.P., Eds.; Kluwer Acadmeic/Plenum Publishers: New York, NY, USA, 2003; pp. 35-54.

95. Kanatzidis, M.G. Structural evolution and phase homologies for "design" and prediction of solid-state compounds. Acc. Chem. Res. 2005, 38, 361-370.

96. Makovicky, E. Crystal structures of sulfides and other chalcogenides. Rev. Mineral. Geochem. 2006, 61, 7-125.

97. Segawa, K.; Taskin, A.A.; Ando, Y. $\mathrm{Pb}_{5} \mathrm{Bi}_{24} \mathrm{Se}_{41}$ : A new member of the homologous series forming topological insulator heterostructures. J. Solid State Chem. 2015, 221, 196-201.

98. Chung, D.-Y.; Choi, K.-S.; Iordanidis, L.; Schindler, J.L.; Brazis, P.W.; Kannewurf, C.R.; Chen, B.; Hu, S.; Uher, C.; Kanatzidis, M.G. High thermopower and low thermal conductivity in semiconducting ternary K-Bi-Se compounds. Synthesis and properties of $\beta-\mathrm{K}_{2} \mathrm{Bi}_{8} \mathrm{Se}_{13}$ and $\mathrm{K}_{2.5} \mathrm{Bi}_{8.5} \mathrm{Se}_{14}$ and their $\mathrm{Sb}$ analogues. Chem. Mater. 1997, 9, 3060-3071.

99. Chung, D.Y.; Hogan, T.; Brazis, P.; Rocci-Lane, M.; Kannewurf, C.; Bastea, M.; Uher, C.; Kanatzidis, M.G. CsBi4Te6: A high-performance thermoelectric material for low-temperature applications. Science 2000, 287, 1024-1027.

100. Kuznetsova, L.A.; Kuznetsov, V.L.; Rowe, D.M. Thermoelectric properties and crystal structure of ternary compounds in the $\mathrm{Ge}(\mathrm{Sn}, \mathrm{Pb}) \mathrm{Te}-\mathrm{Bi}_{2} \mathrm{Te}_{3}$ systems. J. Phys. Chem. Solids 2000, $61,1269-1274$.

101. Caillat, T.; Huang, C.K.; Fleurial, J.-P.; Snyder, G.J.; Borshchevsky, A. Synthesis and thermoelectric properties of some materials with the $\mathrm{PbBi}_{4} \mathrm{Te}_{7}$ crystal structure. In Proceedings of the 19th International Conference on Thermoelectrics, Cardiff, UK, 20-24 August 2000; Rowe, D.M., Ed.; Babrow Press: Wales, UK, 2000; pp. 151-154.

102. Chung, D.Y.; Hogan, T.P.; Rocci-Lane, M.; Brazis, P.; Ireland, J.R.; Kannewurf, C.R.; Bastea, M.; Uher, C.; Kanatzidis, M.G. A new thermoelectric material: CsBi4Te6. J. Am. Chem. Soc. 2004, 126, 6414-6428.

103. Shelimova, L.E.; Karpinskii, O.G.; Konstantinov, P.P.; Avilov, E.S.; Kretova, M.A.; Lubman, G.U.; Nikhezina, I.Yu.; Zemskov, V.S. Composition and properties of compounds in the $\mathrm{PbSe}_{-} \mathrm{Bi}_{2} \mathrm{Se}_{3}$ system. Inorg. Mater. 2010, 46, 120-126.

104. Zemskov, V.S.; Shelimova, L.E.; Konstantinov, P.P.; Avilov, E.S.; Kretova, M.A.; Nikhezina, I.Y. Thermoelectric materials with low heat conductivity based on $\mathrm{PbSe}_{2} \mathrm{Bi}_{2} \mathrm{Se}_{3}$ compounds. Inorg. Mater. Appl. Res. 2011, 2, 405-413.

105. Zemskov, V.S.; Shelimova, L.E.; Konstantinov, P.P.; Avilov, E.S.; Kretova, M.A.; Nikhezina, I.Yu. Thermoelectric materials based on layered chalcogenides of bismuth and lead. Inorg. Mater. Appl. Res. 2012, 3, 61-68.

106. Kuropatwa, B.A.; Kleinke, H. Thermoelectric properties of stoichiometric compounds in the (SnTe $)_{x}\left(\mathrm{Bi}_{2} \mathrm{Te}_{3}\right)_{y}$ system. Z. Anorg. Allg. Chem. 2012, 638, 2640-2647.

107. Kuropatwa, B.A.; Assoud, A.; Kleinke, H. Effects of cation site substitutions on the thermoelectric performance of layered $\mathrm{SnBi}_{2} \mathrm{Te}_{4}$ utilizing the triel elements $\mathrm{Ga}$, In, and Tl. Z. Anorg. Allg. Chem. 2013, 639, 2411-2420. 
108. Medlin, D.L.; Snyder, G.J. Atomic-scale interfacial structure in rock salt and tetradymite chalcogenide thermoelectric materials. JOM 2013, 65, 390-400.

109. Olvera, A.; Shi, G.G.; Djieutedjeu, H.; Page, A.; Uher, C.; Kioupakis, E.; Poudeu, P.F.P. $\mathrm{Pb}_{7} \mathrm{Bi}_{4} \mathrm{Se}_{13}$ : A lillianite homologue with promising thermoelectric properties. Inorg. Chem. 2015, 54, 746-755.

110. Kauzlarich, S.M.; Brown, S.R.; Snyder, G.J. Zintl phases for thermoelectric devices. Dalton Trans. 2007, 2099-2107.

111. Lefebvre, I.; Szymanski, M.A.; Olivier-Fourcade, J.; Jumas, J.C. Electronic structure of tin monochalcogenides from SnO to SnTe. Phys. Rev. B 1998, 58, 1896-1906.

112. Chattopadhyay, T.; Pannetier, J.; von Schnering, H.G. Neutron diffraction study of the structural phase transition in SnS and SnSe. J. Phys. Chem. Solids 1986, 47, 879-885.

113. Peters, M.J.; McNeil, L.E. High-pressure Mössbauer study of SnSe. Phys. Rev. B 1990, 41, 5893-5897.

114. Fadavieslam, M.R.; Shahtahmasebi, N.; Rezaee-Roknabadi, M.; Bagheri-Mohagheghi, M.M. A study of the photoconductivity and thermoelectric properties of $\operatorname{Sn}_{x} \mathrm{~S}_{y}$ optical semiconductor thin films deposited by the spray pyrolysis technique. Phys. Scr. 2011, 84, 035705:1-035705:8.

115. Tan, Q.; Li, J.F. Thermoelectric properties of Sn-S bulk materials prepared by mechanical alloying and spark plasma sintering. J. Electron. Mater. 2014, 43, 2435-2439.

116. Tan, Q.; Zhao, L.D.; Li, J.F.; Wu, C.F.; Wei, T.R.; Xing, Z.B.; Kanatzidis, M.G. Thermoelectrics with earth abundant elements: Low thermal conductivity and high thermopower in doped SnS. J. Mater. Chem. A 2014, 2, 17302-17306.

117. Sassi, S.; Candolfi, C.; Vaney, J.-B.; Ohorodniichuk, V.; Masschelein, P.; Dauscher, A.; Lenoir, B. Assessment of the thermoelectric performance of polycrystalline p-type SnSe. Appl. Phys. Lett. 2014, 104, 212105:1-212105:4.

118. Chen, C.L.; Wang, H.; Chen, Y.Y.; Day, T.; Snyder, G.J. Thermoelectric properties of $p$-type polycrystalline SnSe doped with Ag. J. Mater. Chem. A 2014, 2, 11171-11176.

119. Carrete, J.; Mingo, N.; Curtarolo, S. Low thermal conductivity and triaxial phononic anisotropy of SnSe. Appl. Phys. Lett. 2014, 105, 101907:1-101907:4.

120. Wasscher, J.D.; Albers, W.; Haas, C. Simple evaluation of the maximum thermoelectric figure of merit, with application to mixed crystals $\mathrm{SnS}_{1-x} \mathrm{Se}_{x}$. Solid-State Electron. 1963, 6, 261-264.

121. Chen, S.; Cai, K.; Zhao, W. The effect of Te doping on the electronic structure and thermoelectric properties of SnSe. Physica B 2012, 407, 4154-4159.

122. Parker, D.; Singh, D.J. First Principles investigations of the thermoelectric behavior of tin sulfide. J. Appl. Phys. 2010, 108, 083712:1-083712:3.

123. Bera, C.; Jacob, S.; Opahle, I.; Gunda, N.S.H.; Chmielowski, R.; Dennler, G.; Madsen, G.K.H. Integrated computational materials discovery of silver doped tin sulfide as a thermoelectric material. Phys. Chem. Chem. Phys. 2014, 16, 19894-19899.

124. Lu, X.; Morelli, D.T.; Xia, Y.; Zhou, F.; Ozolins, V.; Chi, H.; Zhou, X.Y.; Uher, C. High performance thermoelectricity in earth-abundant compounds based on natural mineral tetrahedrites. Adv. Energy Mater. 2013, 3, 342-348. 
125. Chetty, R.; Kumar, D.S.P.; Rogl, G.; Rogl, P.; Bauer, E.; Michor, H.; Suwas, S.; Puchegger, S.; Giester, G.; Mallik, R.C.; et al. Thermoelectric properties of a Mn substituted synthetic tetrahedrite. Phys. Chem. Chem. Phys. 2015, 17, 1716-1727.

126. Suekuni, K.; Kim, F.S.; Nishiate, H.; Ohta, M.; Tanaka, H.I.; Takabatake, T. High-performance thermoelectric minerals: Colusites $\mathrm{Cu}_{26} \mathrm{~V}_{2} \mathrm{M}_{6} \mathrm{~S}_{32}(\mathrm{M}=\mathrm{Ge}, \mathrm{Sn})$. Appl. Phys. Lett. 2014, 105, 132107:1-132107:4.

127. Suekuni, K.; Tsuruta, K.; Ariga, T.; Koyano, M. Thermoelectric properties of mineral tetrahedrites $\mathrm{Cu}_{10} \operatorname{Tr}_{2} \mathrm{Sb}_{4} \mathrm{~S}_{13}$ with low thermal conductivity. Appl. Phys. Express 2012, 5, 051201:1-051201:3.

128. Tsujii, N.; Mori, T. Stability and thermoelectric property of $\mathrm{Cu}_{9} \mathrm{Fe}_{9} \mathrm{~S}_{16}$ : Sulfide mineral as a promising thermoelectric material. MRS Proc. 2014, 1680, doi:10.1557/opl.2014.744.

129. Barbier, T.; Lemoine, P.; Gascoin, S.; Lebedev, O.I.; Kaltzoglou, A.; Vaqueiro, P.; Powell, A.V.; Smith, R.I.; Guilmeau, E. Structural stability of the synthetic thermoelectric ternary and nickel-substituted tetrahedrite phases. J. Alloy. Compd. 2015, 634, 253-262.

(C) 2015 by the authors; licensee MDPI, Basel, Switzerland. This article is an open access article distributed under the terms and conditions of the Creative Commons Attribution license (http://creativecommons.org/licenses/by/4.0/). 